\title{
Effect of computer practice of component gait training facts on choice of ambulation aid and gait pattern by physical therapist assistant students
}

\author{
Beverly R. Born \\ West Virginia University
}

Follow this and additional works at: https://researchrepository.wvu.edu/etd

\section{Recommended Citation}

Born, Beverly R., "Effect of computer practice of component gait training facts on choice of ambulation aid and gait pattern by physical therapist assistant students" (2003). Graduate Theses, Dissertations, and Problem Reports. 2501.

https://researchrepository.wvu.edu/etd/2501

This Dissertation is protected by copyright and/or related rights. It has been brought to you by the The Research Repository @ WVU with permission from the rights-holder(s). You are free to use this Dissertation in any way that is permitted by the copyright and related rights legislation that applies to your use. For other uses you must obtain permission from the rights-holder(s) directly, unless additional rights are indicated by a Creative Commons license in the record and/ or on the work itself. This Dissertation has been accepted for inclusion in WVU Graduate Theses, Dissertations, and Problem Reports collection by an authorized administrator of The Research Repository @ WVU.

For more information, please contact researchrepository@mail.wvu.edu. 


\title{
Effect of Computer Practice of Component Gait Training Facts on Choice of Ambulation Aid and Gait Pattern by Physical Therapist Assistant Students
}

\author{
Beverly R. Born
}

\author{
Dissertation Submitted to the \\ College of Human Resources and Education \\ at West Virginia University \\ in partial fulfillment of the requirements \\ for the degree of
}

Doctor of Education

Julie S. Vargas, Ph. D., Chair Nancy L. Adams, Ph. D. Daniel Hursh, Ph. D. Marybeth Mandich, Ph. D. Richard T. Walls, Ph. D.

Department of Educational Psychology

Morgantown, West Virginia 2003

Key Words: Computer Assisted Instruction; Computer Assisted Testing; Feedback; Physical Therapy 
Abstract

Effect of Computer Practice of Component Gait Training Facts on Choice of Ambulation Aid and Gait Pattern by Physical Therapist Assistant Students

Beverly R. Born

Health care educational programs are challenged to provide efficient and effective instructional strategies to teach students both the foundation knowledge and problem solving skills that they need to provide quality health care services. In the present study, computer-based text passages and quizzes were used to teach physical therapist assistant (PTA) students the component facts and principles needed for the higher level skill of choosing ambulation aids and gait patterns for patients in described clinical scenarios. The research questions were (a) whether learning component gait training skills would result in better ability to choose ambulation aids and gait patterns for patients in clinical scenarios, and (b) whether practicing the component skills to achieve fluency would lead to greater problem solving performance. Periodic application probes were used to test problem solving skill. Learning component subskills did result in better problem solving ability for 7 out of 8 students, and fluency on 3 critical quizzes was positively correlated with higher application test scores. A final problem solving strategy resulted in further learning gains for 5 out of 6 students, but the strategy did not compensate for faulty factual knowledge. Overall, the findings of the study show that learning component facts and principles can lead to better problem solving skill without specific additional instruction. In fact, mastery of the factual knowledge is essential for mastery of a problem solving task. Because effective health care is dependent upon good problem solving skills, these findings suggests that learning will be more efficient if instructional materials contain contingencies to ensure that students master critical foundation skills. 


\section{Acknowledgements}

This research was made possible by eight classes of physical therapist assistant students who taught me far more than I ever taught them. They inspired me to seek better ways of teaching so that they could be excellent physical therapy providers. The members of the class of 2004, who served as participants to provide the data, deserve my special thanks and appreciation.

After any major project is completed, the people behind the scenes who gave assistance when it was needed most deserve the greatest thanks. Suellen Hill proctored exams and supervised laboratory practice for our physical therapist assistant students when I had deadlines that could not be ignored. Susan Goodwin acted as research assistant on short notice and monitored the computer lab while students were working through the learning activities that provided the data for this study. My husband, David, took care of the details of home life so I could give the time and attention to this project that it needed. He even ironed his own shirts. I will always be grateful for his assistance.

I especially want to thank Dr. Julie S. Vargas, my advisor and committee chair, for her guidance. She gently nudged me in a forward direction and inspired me to produce a better product than I might have done if left to set my own standards. My other committee members, Dr. Nancy L. Adams, Dr. Daniel Hursh, Dr. Marybeth Mandich, and Dr. Richard T Walls, also provided assistance and helped me clarify my thinking so that I could convey my ideas in the best way possible. Dr. Carol Parke and Dr. Andrew Katayama provided assistance early in my program of study. I am grateful to my committee for helping me to develop as a learner and as a teacher. 


\section{Table of Contents}

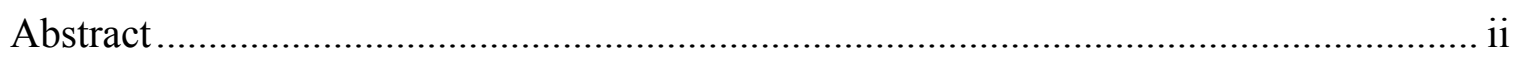

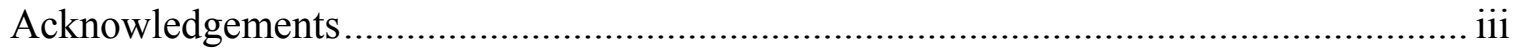

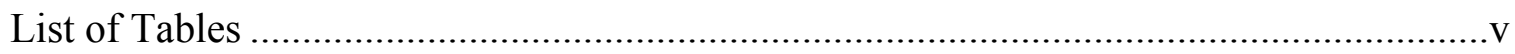

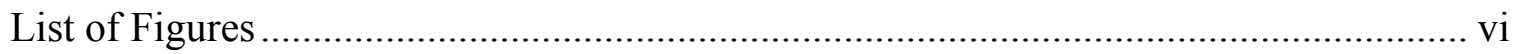

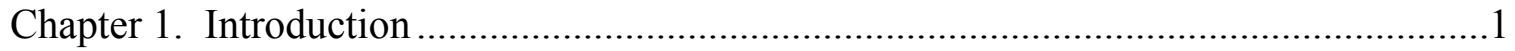

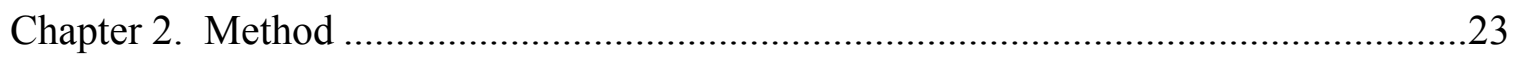

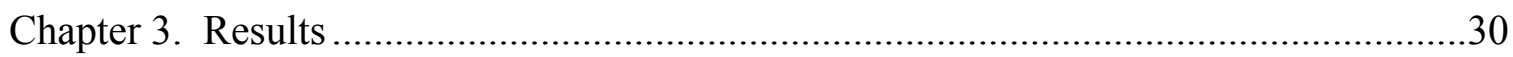

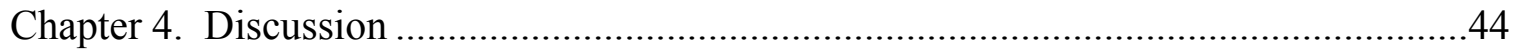

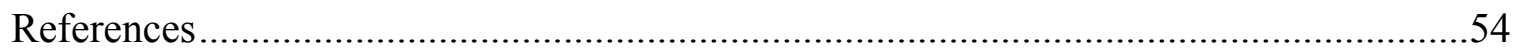

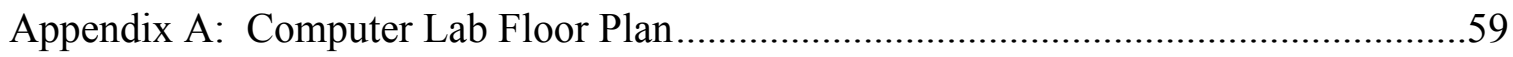

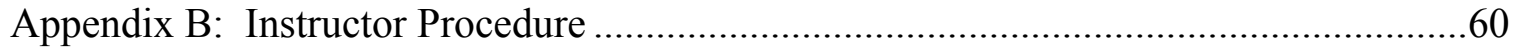

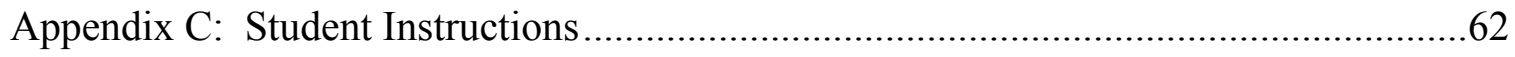

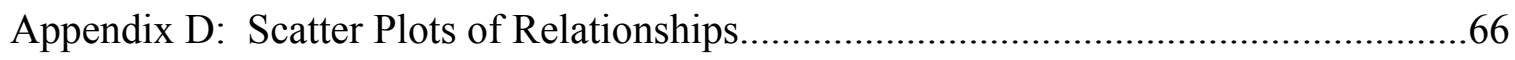

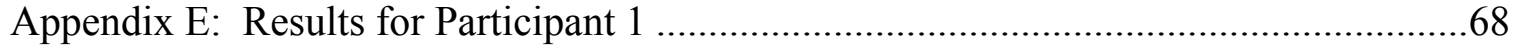

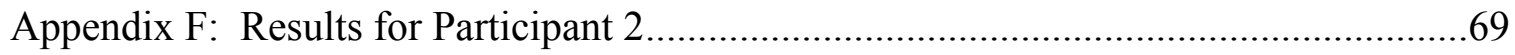

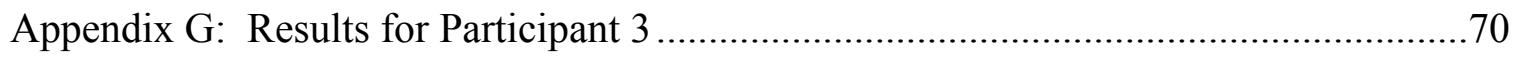

Appendix H: Results for Participant 4 ................................................................ 71

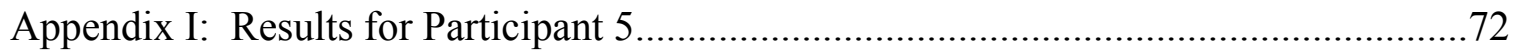

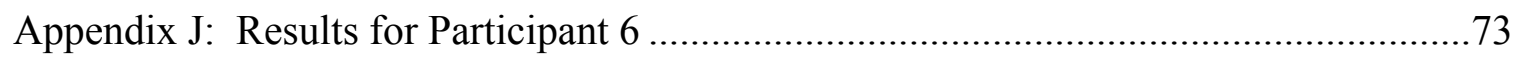

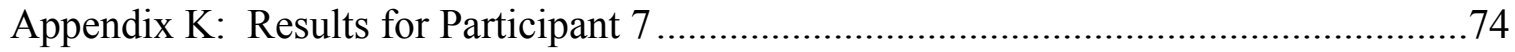

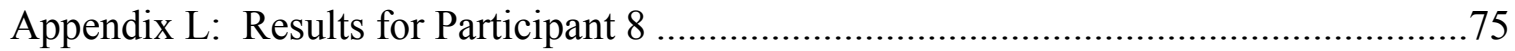

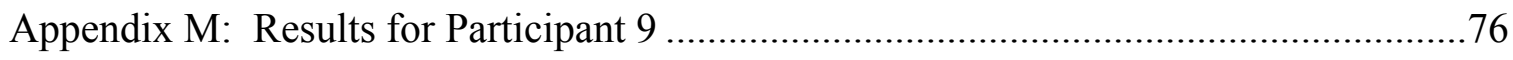

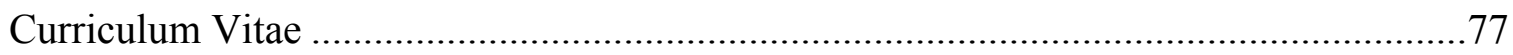




\section{List of Tables}

Table 3.1. Group Assignment According to Pretest Match

Table 3.2. Probe Scores, Instructional Time, Quiz Repetitions,

and Fluency Attained

Table 3.3 Correlations between Final Probe Scores, Instructional Time, Repetitions,

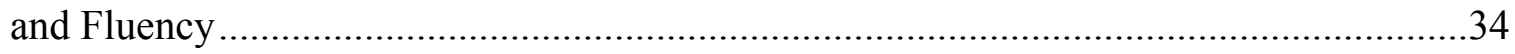

Table 3.4. Correct and Incorrect Baseline Probe Responses for Participant 3 ................37

Table 3.5. Correct and Incorrect Baseline Probe Responses for Participant 6 .................38

Table 3.6. Correct and Incorrect Baseline Probe Responses for Participant 4

Table 3.7. Correct and Incorrect Baseline Probe Responses for Participant 5

. .40

Table 3.8. Correct and Incorrect Baseline Probe Responses for Participant 7 


\section{List of Figures}

Figure 2.1. Research Design Flow Chart .................................................................24

Figure 2.2. Sample text reading window in WebCT format .......................................27

Figure 3.1. Graphed quiz and probe scores for participants who achieved mastery ........36

Figure 3.2. Graphed quiz and probe scores for participant who showed skill loss...........38

Figure 3.3. Graphed quiz and probe scores for participants who received standard

quiz instruction, fluency training, and the problem solving strategy...................39

Figure 3.4. Graphed quiz and probe scores for participants who received fluency training

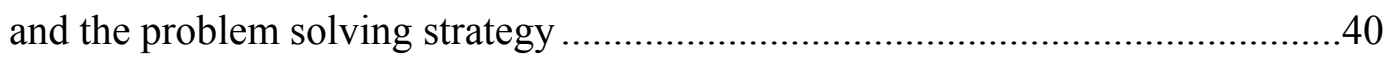




\section{Chapter 1. Introduction}

According to the U.S. Census Bureau, 6,000 Americans currently turn 65 years of age every day, a number that is projected to reach 10,000 by the year 2012 (U.S. Census Bureau, 2000). Consequently, the need for healthcare services is also expected to increase because older people have more health problems, use more medical services, and suffer from more chronic diseases like arthritis and hypertension than do younger people (Kirby, Machlin, \& Thorpe, 2001). Rehabilitation services such as physical therapy help people regain the ability to perform the activities of daily living that they need to live independently. In fact, elderly people who received physical therapy in their homes after a hip fracture improved in the ability to bathe, dress, and prepare meals. Furthermore, patients who received high frequency physical therapy during hospitalization after surgical repair of a hip fracture were able to walk an average of 2.2 days sooner than those who received low frequency therapy (Hoenig, Rubenstein, Sloane, Horner \& Kahn, 1997). Obviously, the number of people qualified to deliver physical therapy services will have to increase over the next few years to provide services for the increasing number of elderly people who would benefit.

Both physical therapists and physical therapist assistants provide physical therapy services. A physical therapist assistant (PTA) works under the supervision of a therapist to give direct patient care by carrying out the treatment plan that the therapist has developed (American Physical Therapy Association, 1999). Teaching patients how to get in and out of bed after a stroke, walk with a walker after a hip fracture, or perform exercises to regain motion following a knee replacement are typical interventions that are delegated to the assistant. An effective PTA must also be able to assess the patient's response to the treatment procedures and make appropriate modifications. For example, if a patient is having too much trouble learning to use crutches the PTA must know when a walker can be substituted or when the therapist should be consulted. PTA education, by necessity, must develop both basic skills and knowledge and more complex problem solving abilities. Because PTA education typically spans only two years, efficient and effective instructional strategies are needed if students are to graduate ready to pass the licensing exam and join the work force to deliver quality physical therapy services.

Students enter PTA programs with greatly varying abilities and experiences. For example, a typical class at Fairmont State College generally includes recent high school 
graduates, students who already have college degrees, and non-traditional students who are attending college for the first time, twenty years after high school graduation. When learning depends on a combination of textbook readings and higher-level exercises in the classroom to apply facts to patient situations, only the more capable students are successful by the end of the allotted time. Some students have not learned the basic knowledge needed for the more difficult applications and others need practice beyond what is available in class. In fact, at the conclusion of the gait training unit for a recent PTA class, only 4 out of 14 students had achieved the highest skill in choosing the appropriate ambulation aid and gait pattern for given patient situations. Designing instructional materials so that all students achieve learning goals is a challenge because of the differing skill levels of students.

Part of the challenge is discovering the best delivery system for instructional materials. When educators evaluate learning, they find that instructional materials that contain all the proper elements are effective regardless of whether they are presented in text, audio, visual, or computer assisted formats (Crooks, Klein, Savenye, \& Leader, 1998). The proper format of instructional materials is especially important when students study at home because the teacher is not physically present to keep students on task and provide feedback. Computer assisted instruction has the advantage of being available outside typical classroom settings and it can be designed to play part of the teacher's role. Consequently, students can repeat self-paced learning assignments until they reach mastery so that even those who require extra practice can be successful. What, then, are the critical elements for effective instructional materials and can they be presented in a computer assisted format?

\section{Literature Review}

\section{Component/Composite}

In physical therapy education, learning goals typically include higher-level application skills that build on a foundation of basic knowledge. Students learn technical facts and principles but need to be able to use them to solve complex clinical problems for which there may not be rules or guidelines. Because of the increasing sophistication of medical knowledge and resulting curricular expansion, physical therapy educators are challenged to teach basic 
knowledge in such a way that problem solving skills also increase (Shepard, Jensen, \& Hislop, 1990; Slaughter, Brown, Gardner, \& Perritt, 1989).

Any type of complex behavior is composed of basic skills and when the simple, component skills are learned first, the complex skills that depend on them are more easily learned or appear without further training (Binder, 1996; Johnson, 1997; Johnson \& Layng, 1992). The fact that the ability to perform a skill can arise as a result of learning something else first is illustrated in stimulus equivalence studies. To develop stimulus equivalence, participants are trained to perform two unrelated tasks. They are then asked to perform a third task that has not been specifically trained but depends upon the two that were previously learned. Much of the research uses match-to-sample tasks with symbols and colors (Rehfeldt, Dixon, Hayes, \& Steele, 1998; Rehfeldt \& Hayes, 2000), geometric shapes (Innis, Lane, Miller, \& Critchfield, 1998), or nonsense symbols (Duarte, Eikeseth, Rosales-Ruiz, \& Baer, 1998; Eikeseth, RosalesRuiz, Duarte, \& Baer, 1997) that are arbitrarily said to form a concept. For example, if participants in studies are trained to match $\mathrm{X}$ to $\mathrm{Y}$, then trained to match $\mathrm{Y}$ to $\mathrm{Z}$, they are judged to have developed stimulus equivalence if they match $\mathrm{X}$ to $\mathrm{Z}$ without further training (Barnes, 1994; Clayton \& Hayes, 1999; Green, Stromer, \& Mackay, 1993). The stimulus equivalence research is useful for demonstrating how learning component tasks may affect composite learning but it does not show that the techniques are useful for teaching in specific subject areas. Fortunately, applied research in education suggests that strengthening component skills is an effective way to increase more complex behaviors.

Much of the research into teaching and remediating reading skills for children focuses on the component skills that make reading proficient (Chard, Vaughn, \& Tyler, 2002). Being able to recognize letter and phoneme sounds, read single words and text passages, comprehend, spell, and write are all component skills of reading (Foorman \& Torgesen, 2001). Research efforts have focused on identifying strategies to improve the component skills to see the effect on overall reading ability. Practice in reading single words has been found to improve the ability to read and comprehend text passages (Levy, Abello, \& Lysynchuk, 1997). Reading passages with a more able peer and taking part in discussions designed to improve comprehension were also tested as means to improve reading skill (Berninger et al., 2002). Similarly, specific instruction 
in spelling and composing were found to be more effective in improving writing skills than writing practice without instruction (Vaughn et al., 2000).

Other research projects show that reading is not the only high-level skill that depends on proficient subskill performance. An example is a study by Evans (1997) in which fifth and sixth grade school children developed the ability to critique works of art as a result of learning component skills. When they were asked to make comments about an artist's work prior to training, they did not have the vocabulary to describe what they were seeing and typical comments were "I like it because it is nice" (Evans, 1997, p48). The students were given flashcards with vocabulary words and worked in groups to choose the words to describe a piece of art. The teacher helped them discriminate among examples of lines, shapes, or colors. At the conclusion of the training, students were more likely to make comments such as "Composition I Storm has diagonal, zigzag, and curved lines of blue, green, red and yellow. It's a loud and exciting painting" (Evans, 1997, p48). Although improvement was not quantified in this study, the anecdotal results suggest that training in vocabulary, a component skill, improved the students' abilities to evaluate works of art.

Whether learning to read single words improves the ability to read and comprehend text passages was tested with elementary students (Levy et al., 1997). In the first of two studies, fourth graders were trained to read single words that were displayed on a computer screen for 2 seconds each. Over the course of the training the average time needed to read a word decreased by 500 milliseconds and the number of errors decreased from 17 to less than one. After training, students read a short story that contained either the trained words or novel words. They read the assigned story three times in succession, and four different comprehension questions were asked after each repetition. The training sequence was repeated with a new word set, and story assignment was counter balanced with the first trial. Analysis of variance showed that the reading time and the number of errors decreased for all students as the stories were re-read. However, the students who were assigned to the stories that contained the trained words made fewer errors and needed less time to read than the students who read the stories that contained novel words. The mean reading time for the first story repetition for the trained group was 225.6 milliseconds with two errors but the untrained group needed 281.1 milliseconds and made 12.6 
errors. The trained group still required less time for the third story reading (171.1 versus 207.9) and made fewer errors (1.0 versus 6.4$)$. As the children practiced reading single words and stories, reading speed increased and the number of errors decreased. Learning to read single words clearly improved the more complex skill of reading entire text passages. However, the ability to answer comprehension questions correctly was unchanged whether students read stories containing trained or untrained words.

The effect of learning component skills on problem solving was demonstrated for college students in a study of math skills. Hazlett (1999) used three training methods to teach rules about exponents and order of operations to undergraduate students. All participants were given work sheets that explained one rule at a time, shown examples of that target rule, and offered practice problems to solve. Participants had to solve 25 problems with no errors for three sessions in a row before they could take an exam and progress to the next rule. In the session before the exam, participants worked review problems. The training methods differed in the type of review problems offered. One group (Cumulative Practice) had review problems from all the previously learned rules. The Simple Review group had practice problems from only one previously learned rule. The review for the last group (Extra Practice) consisted of problems about the most recently learned rule. The behavior of interest in this study was performance on the exam that followed mastery of each rule. Exam items tested rule application and novel problem solving, were of equal difficulty, and covered the same information throughout the study. All of the groups improved in both accuracy and number of correct responses per minute over the course of the training. The Cumulative Practice group answered more test items correctly (97\%) on the sixth and final training test than the Simple Review and Extra Practice groups $(85.36 \%$ and $85.45 \%)$. Furthermore, when outliers were removed, the range of scores for the participants in the Cumulative Practice group varied by only $21 \%$ (79\%-100\%) as compared with 50\% (17\%-67\%) for the Simple Review group and 71\% (4\%-75\%) for the Extra Practice group. In other words, less able student performance was closer to the level of the more able students in the Cumulative Practice group.

Learning component skills appears to facilitate complex task performance for elementary school children (Evans, 1997; Levy et al., 1997). Hazlett (1999) more clearly demonstrated that 
when undergraduates learn component skills, performance on complex tasks improves. Math problem solving, in particular, improved without specific training in problem solving strategies. In all of the studies, the instructional activities targeted the subskills and did not specifically provide practice in the complex activity. Consequently, if the goal of instruction is to develop problem solving ability, then providing practice in the foundation skills is important for learning efficiency.

\section{Active Responding}

The studies that described the importance of component sub-skill mastery for higherlevel skills used instructional techniques that required students to make active responses to the learning materials. When the children learned to critique works of art (Evans, 1997) they used flashcards to name examples of lines, shapes, and colors. Children in the Levy et al. (1997) study were required to name the words that appeared on the computer screen and read the stories aloud. By the end of the training sequence for a word set, they had read each word six times on each of four separate days. Reading the words twenty-four times resulted in shorter story reading times and fewer errors. Similarly, the students who were learning math skills (Hazlett, 1999) worked math problems using worksheets. Over the course of the training sessions they worked similar problems many times and the accuracy and rate of their performance increased.

Other studies describe learning in a variety of subjects, but in all cases students are making active responses to the learning materials. For example, elementary students learned to be better spellers by saying phonetic sounds (Harrington, 1996). Undergraduates responded to materials presented on computer screens to learn biology (Dempsey \& Litchfield, 1993), mathematics (White \& Breit, 1994), anatomy and physiology of the human heart (Williams \& Dwyer, 1996), behavior analysis terms (Kelly \& Crosbie, 1997), and how to distinguish fact from inference in psychological literature (Washburn, 1999). Physical therapy students used computer software or dissection laboratories to learn human gross anatomy (Bukowski, 2002). Students also learned more chemistry when they filled out worksheets and conducted experiments than they did when they listened to lectures and watched the teacher conduct the experiments (Eniaiyeju, 1983). Even when the active student response was listening to the 
teacher give feedback on test answers and making notes or asking questions (Gagne' et al., 1987), more learning was demonstrated than if students passed notes to each other or looked out the windows.

Whereas most of the previous studies showed that active responding is related to learning, Kritch and Bostow (1998) showed that when students make a greater number of active responses more learning occurs. They studied the effect of student-constructed responses during computer assisted instruction to teach component parts of a computer authoring language.

Participants were divided into three groups that differed in the required number of responses to be typed into computer frames of text. The high-density (HD) group had to type a missing word in each of 176 frames of text. The low-density (LD) group members read identical frames, but only half of the frames had missing words that required typed responses. The zero-density group members (ZD) read 176 frames but were not required to type any answers at all. A fourth group (CT) was used to control for time on task. Each member in this group was yoked to a member of the HD group. Although CT participants did not construct responses, they could not advance through the program independently: when the HD partner moved to the next frame, the CT yoked student's computer also advanced. At the conclusion of the learning sequence, participants were asked to write a short computer program applying the information learned in the computer assisted activity. After writing the program code, students completed a computer assested posttest with items that resembled the instructional program.

The results of this study showed that the more responses generated in the instructional sequence, the better the performance on a 34-item computer assisted posttest. In fact, the HD group (85.23\%) scored 10 percentage points higher than the LD group (75.75\%) and almost 30 points higher than the ZD group (63.08\%). Performance on the application test showed similar results but only the difference between HD and ZD scores was significant. For both tests, the mean for HD group scores (76.74\%) was superior to all other group means $(67.59 \%$ LD; $69.55 \%$ CT) and the ZD mean (61.59\%) was inferior. The time needed to complete the instructional program was recorded and compared across groups. As expected, the HD group averaged more than 20 minutes longer on task than LD and 30 minutes more than ZD. The control group (CT) naturally spent the same amount of time on task as HD because of the yoking design, a 
circumstance that may be related to the fact that the CT group scored 7 points higher than the ZD group on the computer assisted posttest. Performance on the application test showed similar results except that the CT group also scored higher than the LD group. Although these differences were not statistically significant, they suggest that in addition to active responding, the amount of time spent with instructional materials may be related to learning.

Katayama and Robinson (2000) also suggest that the number of active responses that students make may be related to learning. They compared factual and application test performance after undergraduates took notes and studied a chapter length text. All of the students studied during class time, but some of the students used notes in outline format and others used a graphic organizer (GO), a two dimensional matrix of rows and columns.

Undergraduates were given the text with complete, partially complete, or skeletal notes to study and the materials were collected at the end of the class session. The study materials differed in the amount of note taking that the students had to do to complete the handout. Those given complete notes did not have to write anything more, those given partial notes had to fill in half of the information, and those with skeletal notes had to write all but the major headings.

The type of study materials that the students used did not affect the factual knowledge that students gained: posttest means (range of 20.33 to 23.68) were not significantly different for any of the groups. The students had access to the study materials for the same amount of time, which resulted in the same factual learning gains. Performance on the 10-item application test, however, suggests that higher-level learning may depend on more than time spent studying. Those with partial notes, either outline $(\mathrm{M}=7.67)$ or $\mathrm{GO}(\mathrm{M}=9.26)$, out performed the students who used complete outline $(M=6.11)$, complete $\mathrm{GO}(\mathrm{M}=7.28)$, skeletal outline $(\mathrm{M}=7.40)$, and skeletal GO $(\mathrm{M}=7.95)$. Making active responses to finish partial notes resulted in a significantly better ability to answer application questions than just studying handouts. The difference in performance between the skeletal and partial note groups was not significant, although the means were greater for the partial notes. The authors speculate that the cognitive load of finishing skeletal notes may interfere with the ability to apply the information. Graphic organizers were also more effective than outlines for helping students learn to apply factual knowledge, suggesting that the type of active response required may also influence learning. 
Evans (1997), Hazlett (1999), and Levy et al. (1997) demonstrated that students learned when they made active responses, but the Kritch and Bostow (1998) study showed that students learned the most component knowledge, and applied it better, when they constructed the most responses to instructional materials. When students controlled the speed at which they read textual materials, as in the ZD group, they did not spend enough time to learn the component parts of the complex task of writing computer code. Katayama and Robinson (2000) also showed that time spent with instructional materials was important for learning but that there may be a point at which the number of active responses becomes counterproductive. Instructional materials that supply the structure for an optimal level of active responding ensure that students take enough time to learn the component information that is critical for higher-level application.

\section{Fluency}

When students learn component skills, accuracy is important, but research suggests that accuracy plus speed, or fluency, helps students learn and retain more. More importantly, fluent learning may also aid application to higher level tasks. Research with disabled subjects shows that requiring high rates of prerequisite skills results in faster learning of more complex skills. Specific instruction for the higher-level skills is not always needed (Binder, 1996). Johnson and Layng (1992), reported multiple examples of the effect of high prerequisite skill fluency rates on more complex application skills: students were able to remember information and retain skills with more accuracy over time, and apply the information better, if they learned the component skills to a very high rate.

Related research in overlearning suggests that repetition of a learning task beyond what is needed to achieve accuracy is beneficial. Overlearning is defined as planned practice of a learning task after a target criterion is reached (Driskell, Willis, \& Copper, 1992). Although the goals of overlearning are generally accuracy based rather than fluency based, repeated practice usually results in faster performance. For example, in the Levy et al. (1997) study, children decreased the time needed to read stories over the course of four readings even though specific time goals were not emphasized. In a study designed to test the effects of overlearning on spelling acquisition and retention (Ormrod \& Spivey, 1990), undergraduates were divided into 
three groups to practice spelling 12 words. One group practiced to mastery, as defined by five consecutive correct spellings. A second group achieved mastery then completed 10 additional trials without time requirements (mastery with overlearning) and the third group completed 10 additional trials after mastery with the requirement to write each word in a 3 -second period (mastery plus speeded overlearning). Performance on an immediate posttest showed that the mastery-only group spelled 7.67 words correctly compared with 10.08 for the overlearning and 10.80 for the speeded overlearning groups. Three weeks later, the overlearning groups $(\mathrm{M}=$ $2.46 \& M=3.50)$ were still performing better than the mastery only group $(M=1.67)$. In this study, the 3-second time requirement during the overlearning trials did not significantly improve learning, however, time data are not presented to indicate whether the overlearning and speeded overlearning groups actually used different time intervals to complete the overlearning training trials.

Other studies have demonstrated that better learning is achieved when fluency is a goal of learning tasks. Ivarie (1986) studied the effect of rate of performance on the retention of elementary school children. One hundred and twenty fourth graders learned to write Roman numerals when given Arabic prompts. Students of above-average, average, and below-average ability were randomly required to achieve a rate of 70 or 35 responses per minute. When students reached the assigned proficiency level they were given alternative activities during the practice sessions so that they would not exceed the target rate. A posttest, given after three months, showed that the students who were required to achieve 70 responses per minute during the practice sessions averaged $97 \%$ correct and those who only met the 35 responses per minute criterion averaged $90 \%$. Posttest scores were recorded as the average percent of correct responses for three one-minute timed tests containing 100 problems each.

It appears that high fluency rates might be even more important for average and belowaverage students than for higher performing students. The average and below-average students who were required to perform at the higher rate scored better on the posttest ( $96 \%$ ) than those who performed at the lower rate $(85.5 \%)$. Posttest scores for above-average students did not show these patterns but were similar regardless of training rate. Variability from low to high score was also related to training rate in that the high-rate group showed an 8 point spread (92\%- 
$100 \%$ ) compared to 23 points (76\%-99\%) for the low-rate group. Less variability between scores suggests that less able student performance was closer to the level of the more able students: therefore, higher fluency rates may be especially helpful for average and below-average learners.

The effect of fluency training on undergraduate learning was demonstrated in a series of studies by Yaber and Malott (1993). Computer flashcards were used to teach psychology undergraduates behavior analysis terms. The flashcards required students to type or say the term when given a definition, or type or say key words when given a term and partial definition. All of the item types were included in a 50-minute study session for each chapter. In addition, students were permitted to browse through the flash cards without responding. In the first experiment, students were required to reach a rate of 5 correct per minute and they were allowed to practice until the fluency criterion was reached or the lab session ended. At the end of each session, they went to class and took a quiz that included 10 terms practiced with the flashcards and 10 that were not practiced. Quiz item types for each chapter varied between matching (6 chapters) and fill-in-the-blank (18 chapters). Fill-in test scores for terms learned with flashcards were higher $(M=73.15)$ than quiz scores for terms studied without $(M=62.74)$. Scores for quizzes with matching items did not differ.

In a follow-up study, the mastery criterion was increased from 5 to 8 correct per minute. Once again, flashcard-trained performance on a fill-in-the-blank quiz was superior $(\mathrm{M}=81.91$ vs. $M=64.42$ ). In addition, the test mean for flashcard trained terms in the second study was almost 9 points greater than in the first $(M=81.91$ vs. $M=73.15)$. The means for the untrained terms were similar in both studies, suggesting that the increase in trained means was related to the increased fluency requirement.

Overall, computer assisted flashcards helped students perform better on quizzes that tested knowledge of behavior analysis terms. Students made active responses to the flashcards (type or say) to achieve mastery and when the fluency rate increased, quiz performance also increased. These findings were only significant when the quiz difficulty was high (fill-in) and not with easier quiz versions (matching), suggesting that fluency rates may have a greater impact when the intended use of the learned material is more difficult. 
The literature on reading instruction for children also advocates fluency training for the component skills of word recognition, phrasing, and prosodic reading to achieve improvement in oral and silent reading and comprehension (Hoffman \& Isaacs, 1991; Meyer \& Felton, 1999; Rasinski, 1990; Stayter \& Allington, 1991). In the second study in the Levy et al. (1997) series, fourth graders were again trained to read single words, but the time that a word was displayed on a computer screen was decreased from 2 seconds to 1.5 seconds. Once again, students were able to read stories that contained the trained words faster and with fewer errors than stories that contained untrained words. Additionally, students were able to answer more comprehension questions correctly when they had been trained on the content words before reading the story. For the first reading, the mean number of comprehension questions answered correctly was 1.53 for stories that contained trained words and 1.05 for the untrained stories. This finding is contrary to the first study and appeared despite the fact that each word in the second study had fewer training trials than those in the first study (20 versus 24). Both studies show that learning to read single words improves the speed and accuracy of reading stories, but it seems that learning the single words at a faster rate also improves the ability to comprehend what is read. It may be important to find the optimum fluency rate for component tasks to maximize the effect on higher level skills.

The relationship between fluency of component skills and performance of more complex behaviors was examined in a slightly different way in a longitudinal study of reading skills (Meyer, Wood, Hart, \& Felton, 1998). Performance on rapid naming tasks in the third grade was used to predict single-word reading ability in the fifth and eighth grades. In rapid naming tasks students name items pictured on cards. Fifty items are pictured on each card and students name them as quickly as possible. Results are scored according to time taken and number of errors made. Low rapid naming scores in the third grade did not predict future reading ability, but students who had low single word reading ability in the fifth and eighth grades had low rapid naming rates in the third grade. There was no correlation between rapid reading scores and later reading ability for students who had average or above average reading ability in later years. There was also no relationship between rapid naming ability and future reading comprehension. 
Unlike the Levy et al. (1997) study, the authors conclude that single word reading ability may not be the only important component skill for reading comprehension.

The effects of component skill fluency on the performance of a composite task was examined in a study by Bucklin, Dickinson, \& Brethower (2000). Undergraduates used flashcards to learn arbitrary word pairs that they would later combine to solve simple arithmetic problems. One component task taught them to match Hebrew symbols with nonsense symbols and the other trained matches between the same nonsense symbols and Arabic numerals. The composite test used worksheets with addition problems written with Hebrew symbols that the participants were required to answer with Arabic numerals. The relationships between Hebrew symbols and Arabic numerals were not trained, so the participants had to rely upon the relationships with nonsense syllables that they had learned. The speed and accuracy of performance on the composite arithmetic test was the behavior of interest, both immediately following training and at regular intervals over 16 weeks following training.

The component tasks were trained to accuracy for all participants. Those who were assigned to the fluency group continued to practice to achieve rates of 50 per minute for the Hebrew-nonsense pairs and 100 per minute for the nonsense-Arabic pairs. The accuracy-only group was given a timed trial at the end of accuracy training to ascertain whether fluency had inadvertently developed. None had developed fluency at the lower criteria of 40 and 70 responses per minute. All participants took a composite test immediately following training, and retention tests were given at either 2 or 4-week intervals with all participants taking the final retention test 16 weeks after training. The component training pairs were also retested at 16 weeks.

The participants were very accurate in performance of the composite skill immediately following training with no significant difference between the accuracy-only group mean of $86.20 \%$ correct and the fluency group mean of $92.52 \%$ correct. However, the fluency group was much faster and averaged 17.27 correct responses per minute compared with 8.97 for the accuracy-only group.

The immediate posttest results of this study suggest that fluency training may not be beneficial unless many, quick responses are needed for a skill. However, fluency training 
resulted in dramatic retention of accuracy over 16 weeks. The fluency group that was tested at 4week intervals decreased $33.04 \%$ in accuracy from the end-of-training composite test to the retention test at 16 weeks. The accuracy-only group lost $75.69 \%$. The groups that were tested for retention at 2-week intervals lost slightly less accuracy: $24.13 \%$ for the fluency group and $73.89 \%$ for the accuracy-only group. Similar results were found for the retention of the component skills. The fluency group decreased by $17.3 \%$ correct on the Hebrew-nonsense pairs compared with $86.20 \%$ for the accuracy-only group. Losses for the nonsense-Arabic pairs were $6.70 \%$ and $69.5 \%$.

Clearly, learning component skills to a high rate of speed and accuracy enables the learner to perform a more complex task better and for a longer time. It seems that if teachers want students to retain what is learned, practice should continue beyond the time needed for accuracy alone. Fluency develops with repeated practice and learning persists as a result. Component practice to achieve fluency may be a way to help all students, particularly low achieving ones, reach the same level of complex problem solving ability.

\section{Feedback}

Component/composite and fluency research have demonstrated that when sub-skills are trained to a high criterion level, the skills combine to produce more complex problem solving behavior without specific training. Furthermore, when the training procedures require active responding by the learner, both basic skill acquisition and novel problem solving are enhanced. How active responding leads to learning is best explained by Skinner's (1953) description of operant conditioning: behaviors that are reinforced continue to occur and those that are not cease. When a response is reinforced, it is more likely to be repeated when the same discriminative stimulus is present. When the response is only emitted in the presence of relevant stimuli, discrimination has occurred. Through the process of reinforcement of correct responses and extinction of incorrect responses, behavior can be brought under precise stimulus control. This form of discrimination training is common in education when a specific answer, the response, is desired as a consequence of a specific question, the stimulus. Reinforcement following active responses is critical for learning to occur. 
Feedback Style. The operant paradigm, outlined by Skinner, relies upon the power of reinforcement for learning. Educational reinforcement can be in the form of external rewards that are delivered by the teacher, such as praise or prizes. Learners are also reinforced by knowing whether or not they are learning (Dempsey \& Litchfield, 1993; Skinner, 1953; White, 1993) so feedback about the correctness of responses is effective. When computers are used to deliver instructional materials, computer use itself can be reinforcing (Waldrop, 1984), but the computer can also be programmed to supply feedback in several different forms. With an answer-until-correct (AUC) style, students repeat a multiple-choice question until the correct answer is selected. Then, the program supplies feedback, usually in the form of "correct" and advancement to the next problem. Knowledge-of-correct-response (KCR) technique tells the student the correct response after an incorrect answer has been given, followed by presentation of the next problem. Elaborative feedback provides additional text information about why an answer is correct or incorrect. The effect of these types of computer delivered feedback on the learning of elementary, high school, and college students has been demonstrated in various studies.

Clariana (1990) studied the effects of KCR and AUC feedback for low-ability learners. Eleventh grade students read paper-based social studies text then answered computer assisted multiple-choice questions. A computer screen presented a multiple-choice question followed by a feedback screen. The correct response was indicated on the feedback screen for the KCR groups, regardless of the student answer. Students in the AUC groups were given another chance to respond if the first response was incorrect. After the second response, the correct answer was indicated. Feedback was given in a full or focused fashion. Focused feedback supplied KCR by showing only the correct alternative, and full feedback showed the distracters and the correct response. In this study, KCR feedback resulted in higher posttest scores $(\mathrm{M}=$ 13.6 for full feedback and $M=13.0$ for focused feedback) than AUC scores $(M=11.6$ for full feedback and $\mathrm{M}=12.0$ for focused feedback) when posttest items were identical to training items. Posttest scores for paraphrased test items were also higher after KCR feedback $(\mathrm{M}=9.6$ for full feedback and $M=11.3$ for focused feedback) than for AUC (M = 9.0 for full feedback and $\mathrm{M}=8.4$ for focused feedback). Test performance was better for test items that were 
identical to training items than for paraphrased items. Whether feedback was full or focused did not appear to have an effect on posttest scores. Clariana suggests that if computer assisted quizzes are used for teaching low-ability students, feedback should include knowledge-ofcorrect-response for better learning. This recommendation applies whether learning is measured by posttests with identical or paraphrased test items.

The primary effectiveness of knowledge-of-correct-response feedback was demonstrated in a later series of studies by Clariana (1993). Third and fourth grade students used computer assisted multiple-choice questions to learn about the solar system in a series of four lessons. All of the lessons provided KCR feedback but two provided full feedback with all of the alternatives for the question shown along with the correct answer. The other two lessons provided focused feedback with only the correct alternative shown. In addition, half of the lessons presented the study questions in random order and the other half presented the questions in a logical order that resembled expository text. The students were given a posttest with random-order items immediately following the lessons, and there were no significant differences in learning for the full and focused feedback lessons. An analysis of variance showed that random presentation of the lesson multiple-choice questions had a negative effect on learning for the older students, but not the younger ones. The study was repeated with eighth grade students and similar results were obtained. Once again, there was no difference in learning for full or focused feedback, and disorganized lessons had a negative effect.

The results of these studies suggest that knowing whether or not they answered the questions correctly was sufficient for learning in elementary and middle school children. Providing the incorrect alternatives along with KCR did not affect learning. However, presenting the multiple-choice lessons in an organized fashion increased learning for older, more able students.

A study by Dempsey and Litchfield (1993) also demonstrates that telling students whether or not they answered multiple-choice questions correctly was sufficient reinforcement for learning. Undergraduates were divided into four groups to use multiple-choice questions to learn biology principles. The groups differed in the type of feedback they received during computer assisted instruction: (a) KCR; (b) KCR plus type the correct answer; (c) KCR plus 
elaborated feedback about an anticipated wrong answer; (d) KCR plus a second try. A control group received the same classroom and textbook instruction that the computer group received. A paper and pencil retention test was given two weeks after the learning session and showed no difference in performance between the four feedback groups $(\mathrm{M}=77.88 \%)$ although they outperformed the control group $(\mathrm{M}=63.49 \%)$. More learning was achieved when multiple choice questions with feedback were used to supplement regular instruction, but more time was spent learning. In addition, the kind of feedback that the groups received significantly affected total instructional time. The simple KCR group used half as much time $(71.76 \mathrm{~s})$ to complete the learning sequence as the KCR plus type the correct answer (197.37 s), KCR plus elaborated feedback (129.28 s), and KCR plus second try (219.16 s) groups did. More learning did not occur when the students spent more time responding to feedback.

It appears that when elementary, high school, or college students use multiple-choice questions to learn, knowledge-of-correct results feedback is effective and time efficient and feedback that consumes more time does not result in more learning. This finding may not be true when the responses that students make require more effort than selecting an answer from a series of alternatives. In a study where students answered multiple-choice or fill-in questions, the type of question that they answered and the feedback they received resulted in different learning (Clariana \& Lee, 2001). Graduate students were divided among five experimental conditions and used computer delivered instruction to learn to define instructional design terms. Each group responded to the learning questions and received feedback in a different way: (a) multiple-choice with KCR after a single try; (b) multiple-choice with KCR after multiple tries; (c) single-try, and if incorrect, KCR and type correct answer; (d) multiple-try, and if incorrect, KCR and type correct answer; (d) fill-in question with KCR after two tries. All of the groups made a similar number of errors during the learning sequence, but the results of a 35 -item fill-in posttest indicated differences in learning related to group assignment. The single-try group scored the lowest $(M=15.09)$ followed by the multiple-try group $(M=15.92)$. The fill-in group $(M=16.96)$ scored lower than the single-try plus fill-in group $(M=19.00)$. The multiple-try plus fill-in group had the highest posttest score $(M=19.5)$. The mean for the group that only constructed fill-in responses during the learning sequence was not significantly greater than for 
the group that only answered multiple-choice questions (16.96 versus 15.09 and 15.92). The best learning occurred with a combination of the two techniques: multiple-choice questions that required students to type the correct answer after receiving feedback for an incorrect response resulted in greater posttest scores. Time spent in the instructional sequence was also different for the groups. The fill-in (2,076 s) and single-try plus fill-in (1,698 s) groups spent significantly more time studying than the single-try $(1,565 \mathrm{~s})$, multiple-try $(1,622 \mathrm{~s})$ and multiple-try plus fillin $(1,560 \mathrm{~s})$ groups. In this study, students who received more elaborate feedback than just knowledge-of-correct-results learned more but not at a cost of more time spent learning.

Feedback Timing. Feedback in all of the previously mentioned studies was delivered immediately after the student responded to a question. Timing can be adjusted so that there is a delay between responding and receiving feedback. In a series of studies, Schroth $(1995,1997)$ investigated the effects of 0,10 , and 30 second delays between student response and feedback. In all of the studies, undergraduates learned to identify concepts arbitrarily formed from a combination of color, form, and size. They were shown cards that were printed with symbols and were asked to tell whether the symbol was an example of the concept. They were told whether they were incorrect or correct immediately, after 10 seconds, after 30 seconds, or randomly varied between 10 and 30 seconds. For example, the number of trials required to identify a red $\mathrm{O}$, regardless of size, as a concept was recorded. Transfer tests were conducted to determine the number of trials needed to identify new concepts. In the initial learning task in the 1995 study, immediate feedback resulted in faster acquisition of the concept: the 0-s group needed 31.98 trials compared with 36.05 for the $10-\mathrm{s}, 50.21$ for the $30-\mathrm{s}$, and 48.93 for the variable 10-30 group. The number of trials students needed to learn similar concepts in a second trial immediately after the first learning task and seven days later were reversed. On the transfer tasks, the 0 -s group took more trials (38.55) than the 10-s (34.63), 30-s (28.19) and variable 1030 (24.38) groups. These results were replicated in a second experiment in the 1995 study and in two experiments in the 1997 study. It seems that feedback timing that results in faster acquisition of a concept interferes with transfer to a similar task. In other words, conditions that make initial learning more difficult may be beneficial for transfer to later tasks. 
Optimal feedback timing may also be related to what students are expected to learn and how they will be tested. Kulik and Kulik (1988) conducted a meta-analysis of the learning effects of immediate versus delayed feedback. Studies were included in the analysis if they reported quantitative data, compared immediate feedback groups to delayed groups, and were published in reputable sources. In other words, they did not analyze studies that relied on anecdotal evidence or were privately circulated. They found that "When test-item stems are used as the stimulus material and the correct answer is the response to be learned, delayed feedback is reliably superior to immediate feedback" (Kulik \& Kulik, 1988, p. 80). Most of the studies gave feedback following completion of the training test, or one to two days later. Immediate feedback, however, was superior to delayed feedback in classroom settings when students were tested with exams that were different from the teaching materials "Nine of 11 studies of this type found that students achieved more in classrooms where they received immediate rather than delayed feedback (Kulik \& Kulik, 1988, p. 89).

The meta-analysis results indicate that optimal feedback timing may depend on what it is that students are expected to learn or at least on how they are to be tested. When students are to be tested in a format that is different from the instructional materials, feedback should follow response as quickly as possible. If the test is identical to the training materials, delayed feedback seems to result in better learning and retention.

Using computers to deliver instruction in the form of multiple-choice or fill-in questions is an effective way to teach facts and principles and feedback helps students learn. The most important characteristic for feedback is that it gives knowledge-of-correct-results. More elaborate feedback may be helpful for more able students, but it may add instructional time without a corresponding increase in learning for less able students.

\section{Instructional Design}

When students need to learn and retain foundation facts and develop the ability to solve complex problems, the instructional sequence should identify the important component skills to be mastered. The key elements for learning materials are opportunity for active responses, followed by reinforcement in the form of feedback, with a sufficient number of learning trials for 
the student to gain fluency. When computers are used for learning, multiple-choice questions are an effective format. Computer delivered feedback should be in the form of knowledge-ofcorrect-response rather than answer-until-correct. More elaborate feedback may be inefficient and consume more time without a resultant gain in learning, especially for lower ability learners. More able students, however, may benefit from elaborated feedback if it is available. The timing of feedback depends upon how learning is to be measured: if the teaching and testing formats are identical, feedback should be given at the end of the training test, or not more than one or two days later. Furthermore, when the ability to transfer learning is desired, delayed feedback is more effective than immediate feedback.

\section{Statement of the Problem}

The primary job responsibility of a physical therapist assistant (PTA) is to implement the treatment interventions requested in a patient care plan developed by a physical therapist. This can involve choosing specific details for the intervention when given the goal of treatment, the patient's present level of functioning, and any special considerations. Gait training is a frequently requested intervention and a PTA may be required to choose the appropriate ambulation aid and gait pattern to satisfy the requirements in the care plan. Consequently, a physical therapist assistant educational program should provide opportunities for each student to develop competence in planning gait training sessions.

Choosing appropriate ambulation aids and gait patterns involves making a series of decisions based on relevant facts about gait training and patient characteristics. The types of ambulation aids, the gait patterns associated with each one, and the physical problem that each aid is designed to ameliorate are examples of component parts of the complex task. According to component/composite research, learning the important foundation knowledge can facilitate decision making, perhaps without specific additional training. This is especially true if the component parts are learned at a high rate of accuracy and speed. It is not clear, however, whether additional repetition to achieve fluency in gait training knowledge leads to improvement in application skills. 
Students do have to make active responses and receive feedback about accuracy for the best learning to occur. For this reason, reading textbooks at home alone is not sufficient for learning for most students, at least not for PTA students who are trying to learn gait training theory. If students fail to master clinical decision making for gait training through traditional text reading and classroom discussion, then an alternative delivery system needs to be developed that will provide the necessary elements for learning and allow students to practice individually until they achieve mastery.

Computer assisted instruction can be designed for self-paced learning that is available at any time and for any number of repetitions. Students can be required to make active responses to the learning materials, both to ensure engagement and to create an opportunity for feedback. When quizzes are used for teaching, every test item requires an active response and provides feedback. The specific feedback style is important, and knowledge-of-correct-response leads to better learning than answer-until-correct. Timing of feedback delivery is also a factor in learning. If student learning is to be tested with items that are identical to the training items, and transfer of learning is desired, then feedback should be delayed at least until the end of the teaching quiz. Computer assisted teaching quizzes are suitable for learning basic facts and can easily be structured to provide well-timed, knowledge-of-correct-response feedback and allow repetition to achieve fluency aims so that learning is maximized. Optional, elaborated feedback can be provided for those students who want to view it so that learning time is not increased unnecessarily for all students.

\section{Current Study}

Students enter PTA programs of study with varying degrees of academic preparation, consequently instructional materials need to be adaptive so that all students can be successful. For this reason, a study that evaluates the effect of learning activities on each student individually will be more likely to identify those that are most helpful to the most students. A single-case research design is sensitive to changes in individual student learning and does not rely upon statistical significance between groups (Kazdin, 1982). When a class of students engages in a learning project, some may learn a lot but others may only learn a little. A single- 
case research design allows changes in learning to be linked with changes in instructional materials so that it is possible to tell where learning occurred or stopped (Barlow \& Hensen, 1984). If the behavior of interest is shown to be occurring at a stable rate and changes when and only when the planned intervention is introduced, then it is likely that the change is a result of the intervention (Barlow \& Hensen, 1984; Kazdin, 1982; Sidman, 1960). In addition, the singlesubject research design increases the validity of the instructional techniques if the obtained effects are replicated across multiple participants.

The present study used a single-case research design to examine whether computer assisted learning of component skills is a way to develop the ability of PTA students to choose appropriate therapeutic interventions without additional problem solving practice. Specifically, students used computer assisted learning activities in a computer lab to learn important gait training terms and theory. Whether learning the component skills to fluency had a different effect on learning was also examined. The behavior of interest was whether PTA students could choose the best ambulation aid and gait pattern for a patient when given a combination of patient facts and characteristics. The ability to choose was tested with multiple-choice quiz items that contained four plausible alternatives. Although an experienced PTA is expected to make a decision without a list of options, in practice there are only three basic ambulation aids and five basic gait patterns from which to choose. Nearly the same decision making process is involved in choosing from four alternatives and more closely approximates the skill level needed by a newly graduated PTA. 


\section{Chapter 2. Method}

This study was designed to compare different methods for learning component parts of gait training knowledge and to determine whether learning the components affected the ability to answer more complex application questions. A single-subject research design was used so that the effect of the instructional materials on the learning of each individual participant could be analyzed. However, participants completed the learning activities anonymously and names were never associated with the data.

\section{Participants and Setting}

Nine physical therapist assistant students enrolled in the PTA program at Fairmont State Community and Technical College served as participants. The students were enrolled in an introductory physical therapy course taken during the second semester of a two-year program. Gait training is always taught in this course, and enrolled students have been required to complete similar learning activities for the past two years. This class of students was also required to complete the activities but whether or not they agreed to allow their data to be included for analysis was voluntary. Students were given homework points for completing the activities.

The college experience for the participants ( 6 women; 3 men) ranged from a high of an earned bachelors degree to a low of being a second semester traditional sophomore. Although all of the students had previous college experience, none had specific instruction in physical therapy theory related to gait training. One student had worked in a physical therapy clinic for a number of years. All of the students had previous experience with the computer software used for the learning activities.

The study was conducted in an institution computer lab during regularly scheduled class time. The 22 X 26 foot lab contained twenty (20) computers each arranged with the monitor under a glass desktop. A floor plan is provided in Appendix A. Each student worked on an individual IBM personal computer.

The study was conducted using WebCT 3.7 software. The learning activities were presented in WebCT quiz tool format, and the correct answer was coded in the software. Student responses were graded and recorded by WebCT. A record of the number of correct responses 
and the time needed for completion of each learning activity was maintained in the WebCT software for each student. Data recording was reliable because responses were computer-scored.

\section{Research Design}

A single subject research design with matched pairs and some features of multiple baselines across participants was used. Participants used computer-based instructional materials to learn component principles of gait training. Whether they also developed clinical problem solving skills was tested through repeated measures of the participants' performance on an application test. Half of the participants began by studying text readings and taking traditional quizzes. The other participants also began with text and quizzes, but they repeated the quizzes until they attained predetermined criteria for accuracy. Both groups took periodic application tests that required use of the component knowledge. Participants who did not attain the desired application skill by the conclusion of the first instructional sequence completed a second sequence. A third sequence was also available. A flow chart of the research design is shown in Figure 2.1.

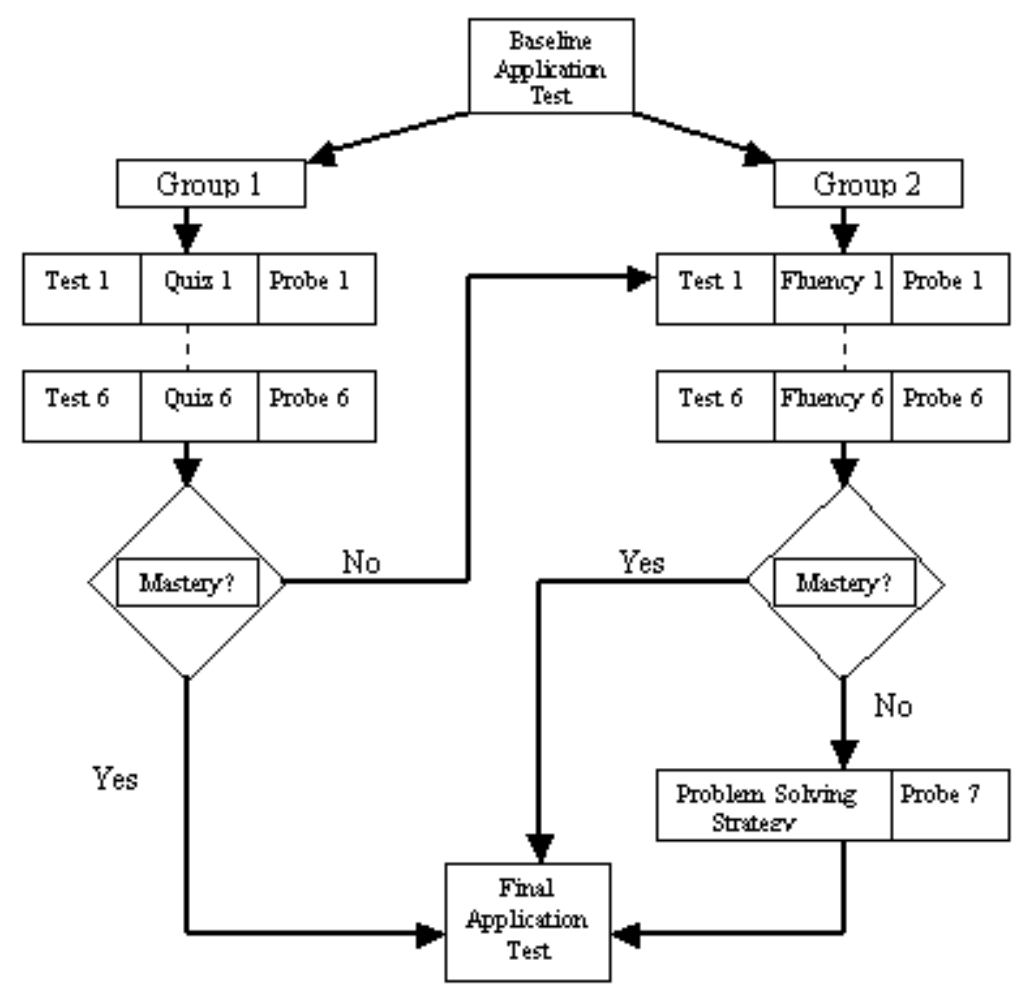

Figure 2.1. Research Design Flow Chart. Group 1 (standard quiz group) followed the sequence on the left of the chart while Group 2 (fluency training group) followed the sequence on the right. 
Each student worked at an individual computer at a self-determined pace during class time. A volunteer who had no connection with the students or PTA program monitored the computer lab during the entire time the participants were working, both during the initial data collection and during the follow-up retention test. She followed written instructions (Appendix B) to inspect the pretest and application test scores for stability and to make group assignments. The participants were also given written instructions (Appendix C).

\section{Procedure}

Application Probe. The performance of students when asked to choose ambulation aids and gait patterns for a described patient was the behavior of interest in this study. The ability was tested through a series of application probes. Multiple-choice questions were used to represent typical patient scenarios. Four alternatives were presented but only one met all of the criteria specified in the problem. Students received feedback as to the probe score, but they were not told which items they answered correctly.

A physical therapy faculty member from another institution was asked to validate the probe items to ensure they represented accurate clinical situations. In addition, an item was selected to be used in the study only if a difficulty index showed that specific gait training knowledge was needed in order to answer the item correctly. Five volunteers who had not received prior physical therapy training were asked to answer 10 trial application test items. The items were presented in random order by WebCT in two separate attempts. Five of the trial application questions were answered incorrectly by the naïve volunteers 9 out of 10 times and were selected for use in the study. The selected items were altered by giving the patients fictitious names. Five additional items were created by changing the patient's name and/or the site of injury to form five additional items that appeared to be different but did not actually differ in the specific gait training knowledge needed to answer the question correctly. Five sets of paired items were established through this process. WebCT randomly selected one item from each pair every time the probe was conducted. The order of the pairs for each probe was randomly determined when the application test was coded into the WebCT software. One of the probe item pairs from the pool of five pairs was as follows: 
Mrs. Ballard is NWB on the LLE. Choose the LEAST restrictive ambulation aid and gait pattern for her.
a. cane; modified 2 point
b. crutches; modified 2 point
c. crutches; 3 point
d. walker; 3 point

Spencer is NWB on the RLE. Choose the LEAST restrictive ambulation aid and gait pattern for this patient.
e. cane; modified 2 point
f. crutches; modified 2 point
g. crutches; 3 point
h. walker; 3 point

A baseline assessment of the ability to answer probe questions was conducted before beginning instruction. In addition, the probe was repeated at the conclusion of each instructional module described below.

Baseline. The five-item application probe was taken to establish a baseline. Students repeated the application probe three or more times until a stable baseline was obtained. Stability was defined as two or more scores at the same or declining level. A stable score of 5 out of 5 indicated a student had mastered the material and did not require further instruction. After the baseline phase, students were divided so that one half began the standard quiz instruction while the other began the fluency training. They were matched according to the pattern of the number of application items they answer correctly during the baseline phase.

Phase 1 (Standard Quiz). The ability to choose ambulation aids and gait patterns was developed through learning activities conducted in WebCT. Half of the students were assigned to the standard quiz phase that was composed of a series of six text readings and corresponding quizzes. The text readings defined terms and explained the relationship of the terms to the clinical problems to be solved. Categories for the readings were (a) basic terms, (b) least and most restrictive ambulation aids, (c) gait patterns to use with each ambulation aid, (d) least and most restrictive gait patterns, (e) patient problems and gait patterns, and (f) patient problems and ambulation aids. The readings were presented in a window like that in Figure 2.2. Students were instructed to study each reading as long as they liked to prepare for the quiz after the 
reading. At the bottom of each reading a question asked if they were ready to take a quiz. They could choose "Yes, I feel ready to take the quiz" or "No, I don't feel ready, but I will move on anyway." The readings were presented in this format so the software could record the amount of time they were displayed and so students would be unable to refer to a reading when taking a quiz.

\section{Close}

An ambulation aide is a device that helps a person walk. Common ambulation aids are walkers, crutches, and canes. A person can use a walker, one crutch, or one cane to walk, or use two crutches or two canes. The best ambulation aid for a patient is the one that gives enough assistance so that the person can walk safely, but does not get in the way of functional activities. The best ambulation aid is LEAST RESTRICTTVE. An ambulation aid that helps a person walk safely, but interferes more with function is called MOST RESTRICTTVE. For example, crutches are less restrictive than a walker because you can go up and down stairs using crutches. Two canes are less restrictive than two crutches because they take up less room. One cane is less restrictive than two canes because one hand is free to carry things. Ambulation aids are listed here from MOST RESTRICTTVE to LEAST RESTRICTTVE: platform walker --> walker --> two crutches $->$ forearm crutches $->$ two canes $->$ one crutch $->>$ one cane. Study the order of ambulation aids. Are you ready to take a quiz?

C 1. Yes, I feel ready to take the quiz.

C 2. No, I don't feel ready, but I will move on anyway.

Figure 2.2. Sample text reading window in WebCT 3.7 format.

The standard quiz for each text reading tested recall of the information presented in that content area. The quizzes were composed of 10 items drawn randomly by the WebCT software from pools of 24-29 items and contained both multiple-choice and fill-in items. An example of each type of question follows: 
1. Select the ambulation aid that is least restrictive.

a. cane

b. walker

2. Ambulation aids that can be used for NWB are walkers and

Students were permitted to view each question only once, but they did not have a time restriction to complete the quiz. The correct response was given at the conclusion of each quiz for both multiple-choice and fill-in items. Multiple-choice questions had additional feedback. If a student chose an incorrect response, feedback explained why the choice was incorrect, such as "No. A cane can't be used with a non-weight bearing gait." Feedback for a correct response reinforced why the answer was correct, as in "Yes. A cane is less restrictive because it is smaller." After completing a reading and its quiz, students took one of the application tests as a probe to check progress on application skill acquisition.

At the conclusion of the sixth assigned instructional module, students repeated the application test until their scores were stable. At this time, stability was defined as no upward trend for the last three tests. If students had stable 5/5 correct scores, they were considered to have mastered the material and needed no further instruction. Those who had not achieved mastery went on to fluency training.

Phase 2 (Fluency Training). After baseline, half of the students were assigned to fluency training. In addition, students who completed the standard quiz phase without reaching application mastery continued with this instructional sequence. As in the standard quiz phase, students read the text passages and took the associated quiz, but they had to repeat the quiz until they achieved a score of at least 9 out of 10 items correct. Students were told that quizzes were to be completed in 2 minutes or less and they were given feedback as to the time used for each quiz. The software was not programmed to reject a quiz if it was submitted after 2 minutes had elapsed to allow the participants to finish the instructional sequence in the available 3 hour class period. WebCT drew the training items at random from the same pools as the reading quizzes and feedback was the same. Each quiz repetition was composed of a different combination of items. Because of the accuracy requirements and the likelihood that participants 
would repeat each quiz, Phase 2 was referred to as fluency training to distinguish it from the single trial quiz version used in Phase 1. Students took an application probe after reading the text and reaching the accuracy criterion for each module and repeated the final application test after the sixth module as needed to demonstrate stability. Once again, students who demonstrated application mastery needed no further instruction. A third phase was provided for students who did not reach the desired performance level on the application probe after reaching the accuracy criterion for all six modules.

Phase 3 (Problem Solving Strategy). A handout (Appendix C) that described a problem solving strategy for answering the application test items was provided to the participants who did not attain mastery in Phase 2. The strategy listed steps to use to eliminate inappropriate response alternatives: (a) Eliminate aides that cannot be used with the weight bearing status that is described; (b) From the alternatives that are left after Step 1, eliminate the aids that are more or less restrictive, depending on what the question asks for; (c) From the alternatives left after Step 2, choose the one with the correct gait pattern; (d) Check for errors. All participants completed the study when application probe score stability was achieved after being given the problem solving strategy regardless of mastery level.

Follow Up. One application test containing five probe items was given to all participants six weeks after the training session to test for retention of specific gait training theory. The same probe items from the instructional phases were used for the follow-up test except that the patient names were removed. One of the probe items was as follows:

The patient is NWB on the LLE. Choose the LEAST restrictive ambulation aid and gait pattern for this patient.
a. cane; modified 2 point
b. crutches; modified 2 point
c. crutches; 3 point
d. walker; 3 point

A final question asked for permission to use the data in this study and each participant responded by selecting yes or no. 


\section{Chapter 3. Results}

Nine PTA students participated in the study by completing the assigned learning activities and gave permission for their data to be analyzed. All of the participants completed the assigned activities within the allotted 3 hour time block and completed the follow-up probe six weeks later.

\section{Pretest}

The behavior of interest in this study was performance on a five-item application test that mimicked the skill needed to choose ambulation aids and gait patterns for patients in clinical settings. The same pool of five matched-pair items was used for the pretest and application probes. Participants completed the pretest at least three times to achieve a stable baseline of two scores at the same or declining levels. Participants 4, 5, and 6 met the stability criteria after three repetitions. Participants 1, 7, and 9 required four repetitions and Participant 3 required five repetitions. Although Participant 2 showed stability after three repetitions, the pretest was repeated for a total of five tests so that one participant would begin the instructional sequence after a longer baseline. Because of a protocol error, the pretest was discontinued for Participant 8 before stability was established.

Five participants were assigned to Group 1 (Standard Quiz) and four were assigned to Group 2 (Fluency Training) when baseline stability was established. Participant 8, however, was assigned to Group 1 even though stability was not obtained. Pretest scores varied a great deal, but group assignment according to similarity in scores was attempted so that the groups would be matched. Pretest scores and group assignments for all participants are shown in Table 3.1. 
Table 3.1. Group Assignment According to Pretest Match

\begin{tabular}{|c|c|c|c|c|c|c|c|}
\hline & & Score 1 & Score 2 & Score 3 & Score 4 & Score 5 & Score 6 \\
\hline \multirow{5}{*}{$\begin{array}{l}\text { Group 1 } \\
\text { Standard Quiz } \\
\mathrm{N}=5\end{array}$} & P 1 & 4 & 4 & 5 & 5 & & \\
\hline & P 3 & 1 & 1 & 2 & 3 & 1 & \\
\hline & P 4 & 3 & 2 & 0 & & & \\
\hline & $\mathrm{P} 5$ & 3 & 3 & 1 & & & \\
\hline & P 8 & 1 & 2 & 3 & & & \\
\hline \multirow{5}{*}{$\begin{array}{l}\text { Group } 2 \\
\text { Fluency Training } \\
\mathrm{N}=4\end{array}$} & & & & & & & \\
\hline & P 2 & 0 & 0 & 0 & 0 & 0 & 0 \\
\hline & P 9 & 2 & 0 & 2 & 2 & & \\
\hline & P 6 & 3 & 4 & 3 & & & \\
\hline & P 7 & 2 & 2 & 3 & 2 & & \\
\hline
\end{tabular}

Note. Scores represent the number correct out of 5 for each of the pretest probes conducted during baseline. $\mathrm{P}=$ Participant.

\section{Data Collected}

Data were collected by WebCT 3.7 software while participants worked through the instructional modules. The score for each quiz and application probe was recorded along with the time taken for completion. During fluency training, the participants were required to achieve a score of 9 out of 10 correct on a quiz before they could progress to the next instructional activity. The recorded data for the fluency quizzes were reviewed to ascertain whether fluency was achieved at the rate of 9 out of 10 correct in 2 minutes or less. The amount of time used for instruction, the number of times quizzes were repeated, and the number of quizzes for which fluency was obtained are recorded in Table 3.2. In addition, all of the individual quizzes were recorded by the software and were reviewed to determine the specific responses that the participants gave for each item. Correct and incorrect responses were tabulated for the baseline probes, probes at the end of Phases 1, 2, and 3, and follow-up probes. The pretest responses for participants who scored greater than 3 out of 5 were examined to determine whether the scores represented a high level of gait training knowledge or were likely to be the result of chance. Tabulations for all of the participants are recorded in Appendixes E through $\mathrm{M}$ and specific individual responses will be highlighted as the results are presented. 
Table 3.2. Probe Scores, Instructional Time, Quiz Repetitions, and Fluency Attained

\begin{tabular}{|c|c|c|c|c|c|c|c|c|c|c|c|c|}
\hline \multirow[t]{2}{*}{ Group } & \multirow[t]{2}{*}{$\mathrm{P}$} & \multicolumn{5}{|c|}{ Phase } & \multirow{2}{*}{$\begin{array}{l}\text { Time in } \\
\text { Seconds }\end{array}$} & \multirow{2}{*}{\begin{tabular}{|c|} 
Quiz \\
Repetitions
\end{tabular}} & \multirow{2}{*}{$\begin{array}{l}\text { Fluent } \\
\text { Quizzes }\end{array}$} & \multirow{2}{*}{$\begin{array}{l}\text { Final } \\
\text { Score }\end{array}$} & \multirow[t]{2}{*}{ Gain } & \multirow[t]{2}{*}{ Loss } \\
\hline & & B & 1 & 2 & 3 & $\mathrm{~F}$ & & & & & & \\
\hline \multirow{5}{*}{$\begin{array}{c}\text { Standard } \\
\text { Quiz }\end{array}$} & $\mathrm{P} 1$ & 4.50 & 5.00 & ---- & ---- & 4.00 & 2,770 & 6 & ---- & 5.00 & +0.05 & -1.00 \\
\hline & P3 & 1.60 & 3.67 & 5.00 & ---- & 4.00 & 4,732 & 16 & 5 & 5.00 & +3.40 & -1.00 \\
\hline & $\mathrm{P} 4$ & 1.67 & 2.17 & 3.00 & 3.29 & 2.00 & 5,389 & 16 & 3 & 3.00 & +1.33 & -1.00 \\
\hline & P5 & 2.33 & 3.33 & 4.67 & 4.00 & 3.00 & 6,923 & 16 & 1 & 4.33 & +2.00 & -1.00 \\
\hline & $\mathrm{P} 8$ & 2.00 & 3.17 & 3.38 & ---- & 2.00 & 6,867 & 18 & 4 & 5.00 & +3.00 & -3.00 \\
\hline \multirow{4}{*}{$\begin{array}{l}\text { Fluency } \\
\text { Training }\end{array}$} & P2 & 0.00 & ---- & 1.67 & 2.00 & 5.00 & 4,630 & 13 & 3 & 2.00 & +2.00 & +3.00 \\
\hline & P6 & 3.33 & ---- & 2.86 & 3.00 & 0.00 & 3,558 & 13 & 3 & 3.00 & -0.33 & -3.00 \\
\hline & P7 & 2.25 & ---- & 2.00 & 3.75 & 2.00 & 3,816 & 12 & 4 & 4.00 & +1.75 & -2.00 \\
\hline & P9 & 1.50 & ---- & 2.17 & 2.40 & 2.00 & 2,953 & 10 & 4 & 3.00 & +1.50 & -1.00 \\
\hline
\end{tabular}

Note. B is baseline. Phase 1 is the standard quiz instruction. Phase 2 is fluency training. Phase 3 is the problem solving strategy. $\mathrm{F}$ is the follow-up. The final score is the mean of the 3 probe scores used to establish stability at the end of instruction. Gain indicates the change between the baseline probe mean and the final score. Loss indicates the change in probe scores from the final score to the follow-up test.

\section{Research Questions}

The primary research question was whether learning component parts of gait training theory would result in better ability to choose ambulation aids and gait patterns for patients in clinical scenarios without specific instruction in the higher level skill. This question was answered affirmatively for the seven out of eight participants (P 2, 3, 4, 5, 7, 8, \& 9) who improved in the problem solving skill after receiving standard quiz instruction, fluency training, or a combination of the two techniques. However, one participant (P 6) who received only fluency training declined in performance. Giving the participants a problem solving strategy to follow when answering the probes resulted in further gains in learning for 5 out of 6 participants (P 2, 4, 6, 7 \& 9). The results for Participant 1, who demonstrated mastery at the end of baseline and did not require instruction, are omitted from statistical analysis.

The secondary research question of whether practicing the component skills to achieve fluency would lead to greater problem solving performance than taking standard quizzes without fluency requirements was only partially answered. Progression through the fluency training modules depended on participants achieving quiz scores of 9 out of 10 correct. Whether or not 
they achieved fluency was judged by inspecting the data to determine if the score was achieved in 2 minutes or less. The number of repetitions for each quiz during fluency training $(\mathrm{M}=1.84)$ was not quite double the one repetition per quiz required during the standard quiz phase. That the participants only repeated the fluency quizzes until the minimum standard was met was unexpected. Earlier in the semester, the same students averaged 4.85 repetitions on six 10-item quizzes that were not related to gait training. They could earn as many as 10 points per quiz and most continued until they earned the full 10 points. The average number of quizzes for which they earned the full 10 points was 4.67 out of a possible 6 quizzes, compared with 2.63 for this study.

Even though the participants in this study did not repeat the quizzes as many times as expected, they developed fluency in more than half of the six quizzes $(M=3.38)$. When the number of quizzes for which fluency was achieved was correlated with the final probe score, there was not a significant relationship (Table 3.3). The relationship is pictured graphically in a scatter plot in Appendix D (Table D1). Three of the modules (Modules 3, 5, \& 6), however, were judged to be critical for solving the clinical problems because errors that were made on the follow-up probe were related to the content taught in those modules. A scatter plot is shown in Appendix D (Table D 2). Furthermore, a correlation for the data revealed that the number of critical quizzes for which fluency was obtained and the final probe score were significantly related, $\mathrm{r}=+.754, \mathrm{n}=8, \mathrm{p}<.05$, two tails (Table 3.3). The relationship of the critical quizzes to persistent probe errors will be discussed further below. 
Table 3.3. Correlations between Final Probe Scores, Instructional Time, Repetitions, and Fluency

\begin{tabular}{lrrrrr}
\hline Measure & 1 & 2 & 3 & 4 & 5 \\
\hline \multicolumn{1}{c}{ Participants $(\mathrm{n}=8)$} & & & \\
1. Fluent Quizzes & ----- & .446 & -.436 & -.124 & .260 \\
2. Fluent Critical Quizzes & & ----- & .213 & .356 & $* .754$ \\
3. Quiz Repetitions & & & ----- & $* * .887$ & .611 \\
4. Instructional Time & & & & ----- & .512 \\
5. Final Probe Score & & & & & - \\
\end{tabular}

Note. $*$ Correlation is significant at the 0.05 level (2-tailed). ** Correlation is significant at the 0.01 level (2-tailed). Data from Participant 1 were omitted from calculation because of mastery during baseline.

\section{Instruction Time and Quiz Repetitions}

The time spent reading and studying the text passages in the standard quiz phase ranged from 412 to 890 seconds with a mean of 636.20 seconds. During the fluency training phase the range was 141 to 1133 seconds with a mean of 550.75 seconds. Every participant who began with standard quiz instruction spent less time reading the identical text passages when presented during fluency training (P 3, 463 \& 396; P 4, 632 \& 404; P 5, 784 \& 141; P 8, 890 \& 570). When total instructional time (reading and quizzes) was calculated, participants who completed both standard instruction and fluency training used more time $(\mathrm{M}=5977.75 \mathrm{~s})$ than those who completed fluency training alone $(\mathrm{M}=3739.25 \mathrm{~s})$. However, when the total amount of time spent on instruction was compared to the final probe score (Table 3.2), more time used for instruction did not necessarily lead to more learning: final probe scores were not significantly correlated with instructional time (Table 3.3; Table D 3).

The total number of quiz repetitions was also compared to the final probe score. The repetitions during standard quiz instruction were added to those in fluency training for a total number of quiz repetitions for each participant. Repetitions ranged from 10 to 18 (Table 3.2), but more repetitions did not necessarily lead to more learning and correlations were not 
significant (Table 3.3; Table D 4). However, repetitions and instructional time were significantly related, $\mathrm{r}=+.887, \mathrm{n}=8, \mathrm{p}<.01$, two tails (Table 3.3). Participants who completed more repetitions were more likely to have received both standard quiz instruction and fluency training, thus spending more time completing instructional activities.

Whether or not participants completed one or multiple quizzes per module did not affect quiz performance: the quiz scores during standard quiz instruction and fluency training both ranged from 3 to 10 out of 10 correct with a mean of 8.37 and 8.26 respectively. However, if only the highest score from the repetitions in each fluency module is considered, the range is 9 or 10 out of 10 correct with a mean of 9.44 .

\section{Individual Participants}

Quiz and probe scores were graphed for individual participants and inspected to determine the change in probe scores during standard quiz instruction, during fluency training, after receipt of the problem solving strategy, and after six weeks. Results for individual participants are grouped according to whether they mastered the learning task, showed a decrease in performance, completed fluency training, or completed both standard instruction and fluency training and are described below.

Participants who achieved mastery. Learning task mastery was defined as stable scores of 5 out of 5 probe items answered correctly. Participants 1,3, and 8 achieved mastery, but at different points in the instructional sequence. Results are graphed in Figure 3.1. 


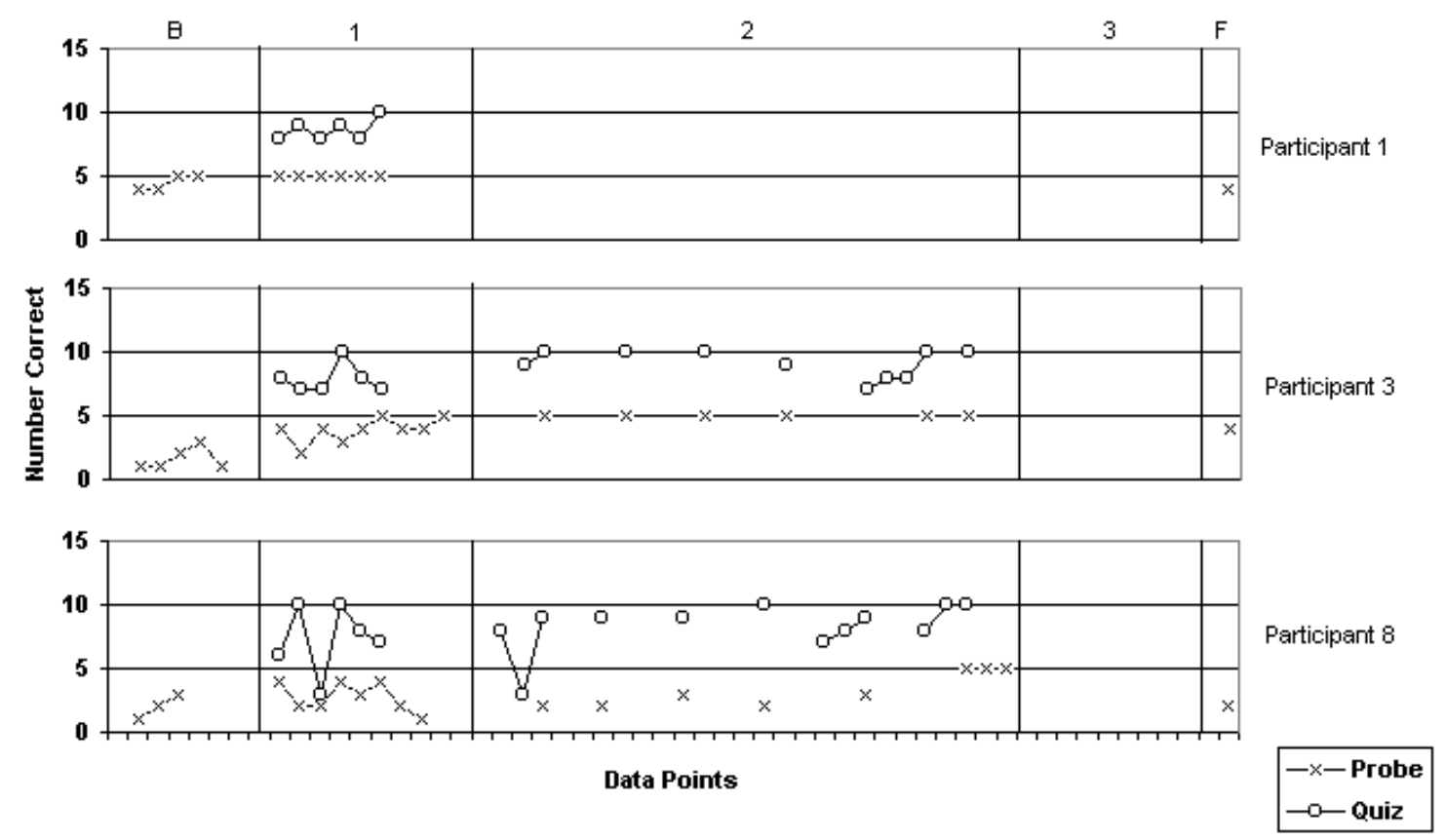

Figure 3.1. Graphed quiz and probe scores for participants who achieved mastery. Baseline (B), standard quiz phase (1), fluency training (2), problem solving strategy (3), and follow-up (F) are represented.

Participant 1 scored 5 out 5 on the two final pretests and satisfied the baseline stability requirement of two or more scores at the same or declining level. Mastery of the behavior of interest, as indicated by the x's in the figure, was achieved at the end of baseline but standard quiz instruction was given because of a protocol error. Although performance was consistently 5 out of 5 correct for six more probes, the retention test score dropped to 4 out of 5 correct. Item analysis showed that the same incorrect response was given to item 3 as had been given in each of the first two pretests: the incorrect alternative paired a walker with 4 point gait and was chosen rather than the alternative that paired a walker with a 3 point gait. A 4 point gait pattern is never used with a walker and the participant's choice of the alternative is an example of a factual error.

Participant 3 scored 3 out of 5 on one of five pretests but examination of the actual items (Table 3.4) shows responses were not consistently correct and most likely represent chance selections. For example, the item pair 3-3A was answered correctly once in the fourth pretest but not in any of the other pretests. Item 2-2A was answered correctly when Mr. Edwards was the 
patient but not when Mrs. Conrad was the patient. Although a probe score of 5 out of 5 was achieved at the end of standard quiz instruction, stability was not obtained because of a protocol error and fluency training was given. Because the probe score continued to be 5 out of 5 during fluency training, it is likely that the learning task was actually mastered during standard quiz instruction. The retention test score was 4 out of 5 correct. The participant chose a cane and modified 2 point gait. Although this ambulation aid and gait pattern is least restrictive, a cane is never correct for a patient who is non-weight bearing. This error that reappeared on the retention test had not been made in the previous 11 probes.

Table 3.4. Correct and Incorrect Baseline Probe Responses for Participant 3

\begin{tabular}{|l|c|c|c|c|c|c|c|c|c|c|}
\hline Probe & Item 1 & Item 1a & Item 2 & Item 2a & Item 3 & Item 3a & Item 4 & Item 4a & Item 5 & Item 5a \\
\hline Pretest 1 & & $\mathrm{X}$ & & $\mathrm{O}$ & & $\mathrm{X}$ & & $\mathrm{X}$ & & $\mathrm{X}$ \\
\hline Pretest 2 & & $\mathrm{O}$ & $\mathrm{X}$ & & $\mathrm{X}$ & & & $\mathrm{X}$ & $\mathrm{X}$ & \\
\hline Pretest 3 & $\mathrm{X}$ & & & $\mathrm{O}$ & $\mathrm{X}$ & & $\mathrm{X}$ & & $\mathrm{O}$ & \\
\hline Pretest 4 & & $\mathrm{O}$ & $\mathrm{X}$ & & $\mathrm{O}$ & & & $\mathrm{X}$ & $\mathrm{O}$ & \\
\hline Pretest 5 & $\mathrm{X}$ & & & $\mathrm{O}$ & & $\mathrm{X}$ & & $\mathrm{X}$ & & $\mathrm{X}$ \\
\hline
\end{tabular}

Note. : O correct; X incorrect. Given one item from each pair.

Baseline stability was not obtained for Participant 8 before beginning instruction because of a protocol error. However, probe scores were so variable during standard quiz instruction it seems unlikely that the participate had a high initial level of gait training knowledge. In fact, the participant persisted in making errors where the alternative chosen was not appropriate for the patient's problem, such as choosing canes for a non-weight bearing gait, until after completing three repetitions on each of the last two fluency quizzes. The appropriate gait patterns and ambulation aids for a patient's problem were expected to be learned in those quizzes.

Participant who showed a loss in skill. The probe mean for Participant 6 declined over the course of fluency training (Figure 3.2). Pretest scores for Participant 6 were very high with three consistently correct responses (Table 3.5) but probe scores never improved during fluency training in spite of 13 fluency quiz repetitions. The follow-up score was the lowest of all the participants and was surprising because two of the items had never been answered incorrectly in the 12 preceding probes. Participant 6 also chose incorrect response alternatives for three of the 
follow-up probe items that none of the other participants chose. It is especially interesting that Item 2-2a, that Participant 6 had never answered incorrectly previously, was not answered incorrectly by any other participant on the follow-up probe.

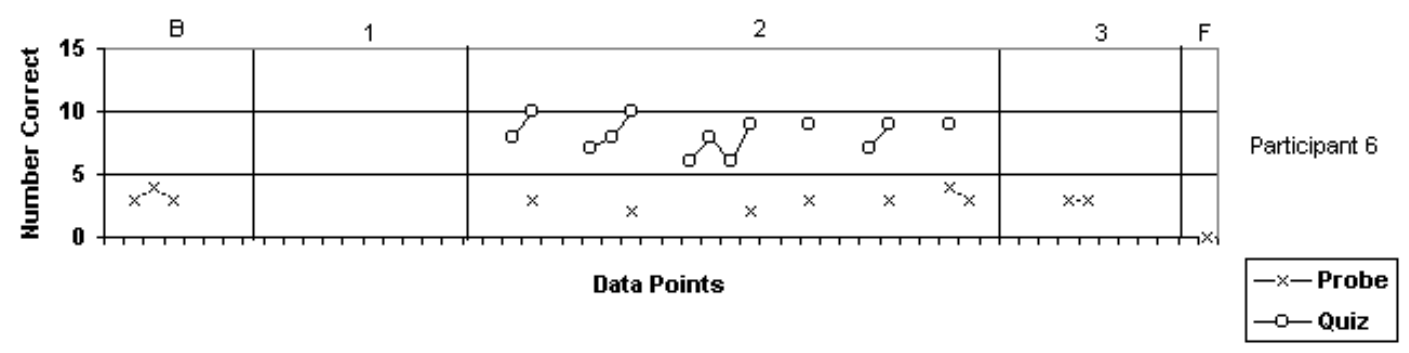

Figure 3.2. Graphed quiz and probe scores for participant who showed skill loss. Baseline (B), standard quiz phase (1), fluency training (2), problem solving strategy (3), and follow-up (F) are represented.

Table 3.5. Correct and Incorrect Baseline Probe Responses for Participant 6

\begin{tabular}{|l|c|c|c|c|c|c|c|c|c|c|}
\hline Probe & Item 1 & Item 1a & Item 2 & Item 2a & Item 3 & Item 3a & Item 4 & Item 4a & Item 5 & Item 5a \\
\hline Pretest 1 & & $\mathrm{X}$ & $\mathrm{O}$ & & & $\mathrm{X}$ & $\mathrm{O}$ & & & $\mathrm{O}$ \\
\hline Pretest 2 & & $\mathrm{O}$ & & $\mathrm{O}$ & $\mathrm{X}$ & & & $\mathrm{O}$ & $\mathrm{O}$ & \\
\hline Pretest 3 & & $\mathrm{X}$ & $\mathrm{O}$ & & $\mathrm{X}$ & & & $\mathrm{O}$ & $\mathrm{O}$ & \\
\hline
\end{tabular}

Note. O correct; X incorrect. Given one item from each pair.

Participants who received standard quiz and fluency training. Participants 4 and 5 received standard quiz instruction, fluency training, and the problem solving strategy (Figure 3.3). Participant 4 scored 3 out of 5 on the first pretest attempt but examination of the actual items (Table3.6) shows that none of the responses were consistently correct. The probe scores increased as the fluency drills were completed. 


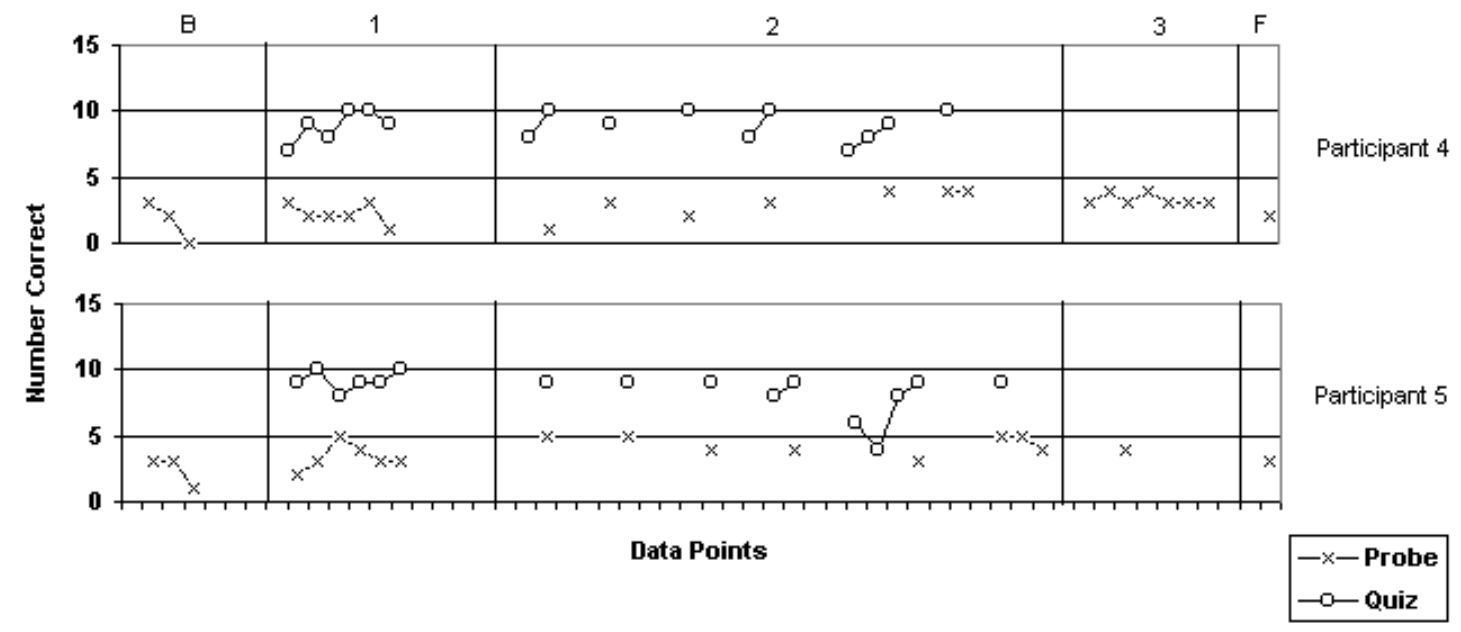

Figure 3.3. Graphed quiz and probe scores for participants who received standard quiz instruction, fluency training, and the problem solving strategy. Baseline (B), standard quiz phase (1), fluency training (2), problem solving strategy (3), and follow-up (F) are represented.

Table 3.6. Correct and Incorrect Baseline Probe Responses for Participant 4

\begin{tabular}{|l|c|c|c|c|c|c|c|c|c|c|}
\hline Probe & Item 1 & Item 1a & Item 2 & Item 2a & Item 3 & Item 3a & Item 4 & Item 4a & Item 5 & Item 5a \\
\hline Pretest 1 & $\mathrm{O}$ & & & $\mathrm{X}$ & & $\mathrm{X}$ & & $\mathrm{O}$ & $\mathrm{O}$ & \\
\hline Pretest 2 & & $\mathrm{X}$ & & $\mathrm{X}$ & & $\mathrm{X}$ & $\mathrm{O}$ & & $\mathrm{O}$ & \\
\hline Pretest 3 & $\mathrm{X}$ & & $\mathrm{X}$ & & & $\mathrm{X}$ & $\mathrm{X}$ & & $\mathrm{X}$ & \\
\hline
\end{tabular}

Note. O correct; X incorrect. Given one item from each pair.

Participant 5 scored 3 out of 5 on the first two pretest attempts but correct responding was consistent for only item 5 (Table3.7). The learning task was nearly mastered at the end of fluency training, but item 5 was answered incorrectly on the last probe. The ambulation aid that was chosen, a crutch, was appropriate for a patient with a balance problem, but was not the least restrictive alternative. The incorrect response for this item is surprising because the participant had chosen a cane correctly in the two previous probes. In fact, the item (5) missed in the last probe during fluency training and after receipt of the problem solving strategy, was the same item that was consistently answered correctly during baseline. 
Table 3.7. Correct and Incorrect Baseline Probe Responses for Participant 5

\begin{tabular}{|l|c|c|c|c|c|c|c|c|c|c|}
\hline Probe & Item 1 & Item 1a & Item 2 & Item 2a & Item 3 & Item 3a & Item 4 & Item 4a & Item 5 & Item 5a \\
\hline Pretest 1 & $\mathrm{X}$ & & $\mathrm{O}$ & & $\mathrm{X}$ & & $\mathrm{O}$ & & $\mathrm{O}$ & \\
\hline Pretest 2 & & $\mathrm{O}$ & $\mathrm{O}$ & & $\mathrm{X}$ & & & $\mathrm{X}$ & $\mathrm{O}$ & \\
\hline Pretest 3 & $\mathrm{X}$ & & $\mathrm{X}$ & & $\mathrm{X}$ & & $\mathrm{X}$ & & $\mathrm{O}$ & \\
\hline
\end{tabular}

Note. O correct; X incorrect. Given one item from each pair.

Participants who received fluency training. Participants 2, 7, and 9 began instruction with fluency training (Figure 3.4) and then received the problem solving strategy. Participant 2 had the lowest baseline scores, and was one of two participants with the most quiz repetitions (13) during fluency training. Even though the probe scores were low at the end of instruction, the participant had a perfect 5 out of 5 score on the follow-up probe.

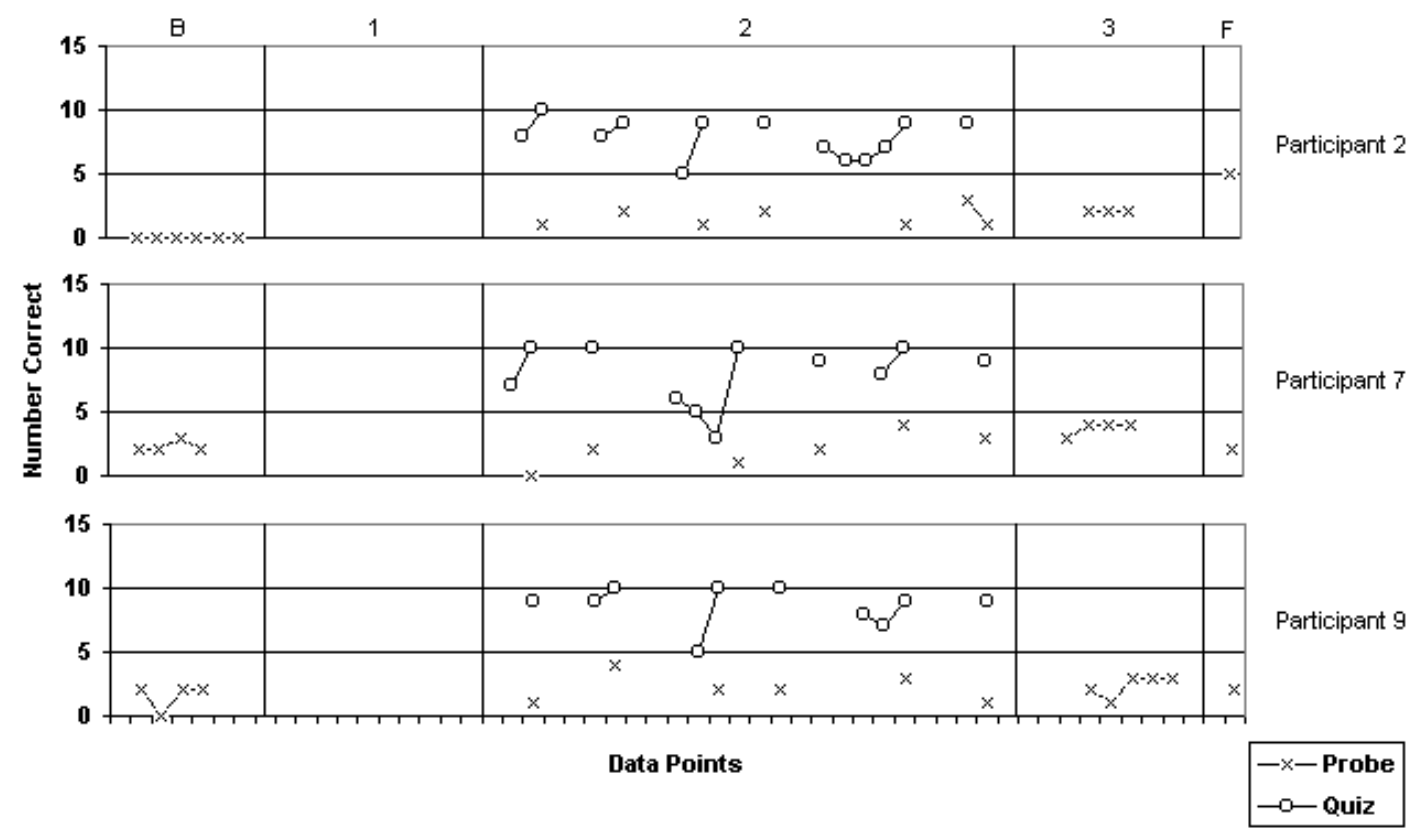

Figure 3.4. Graphed quiz and probe scores for participants who received fluency training and the problem solving strategy. Baseline (B), standard quiz phase (1), fluency training (2), problem solving strategy (3), and follow-up (F) are represented.

Participant 7 obtained a score of 3 out of 5 during baseline but item analysis shows that only one item was consistently answered correctly (Table3.8), suggesting that the other correct 
responses were guesses. Like Participants 4 and 8, the probe scores increased as the fluency drills were completed.

Table 3.8. Correct and Incorrect Baseline Probe Responses for Participant 7

\begin{tabular}{|l|c|c|c|c|c|c|c|c|c|c|}
\hline Probe & Item 1 & Item 1a & Item 2 & Item 2a & Item 3 & Item 3a & Item 4 & Item 4a & Item 5 & Item 5a \\
\hline Pretest 1 & & $\mathrm{X}$ & & $\mathrm{X}$ & $\mathrm{X}$ & & $\mathrm{O}$ & & $\mathrm{O}$ & \\
\hline Pretest 2 & $\mathrm{O}$ & & $\mathrm{X}$ & & & $\mathrm{X}$ & & $\mathrm{O}$ & $\mathrm{X}$ & \\
\hline Pretest 3 & & $\mathrm{X}$ & & $\mathrm{O}$ & $\mathrm{O}$ & & & $\mathrm{O}$ & $\mathrm{X}$ & \\
\hline Pretest 4 & $\mathrm{O}$ & & & $\mathrm{X}$ & $\mathrm{X}$ & & $\mathrm{O}$ & & $\mathrm{X}$ & \\
\hline
\end{tabular}

Note. O correct; X incorrect. Given one item from each pair.

Although, Participant 9 made mean gains during fluency training, performance remained variable with errors relating to the correct ambulation aid and gait pattern for a particular patient problem. Choosing a cane for a non-weight bearing patient and choosing a 2 point gait for a non-weight bearing patient are examples of errors.

\section{Effect of the problem solving strategy.}

Six participants (P 2, 4, 5, 6, 7, \& 9) received the problem solving strategy when they did not master the learning task at the end of fluency training, and all but one (P 5) showed further gains in learning as measured by increases in the probe mean. None of the participants, however, achieved mastery after receipt of the strategy. All of the participants persisted in making errors that reflected inaccurate factual knowledge, for example, choosing the alternative that paired a cane with 3 point gait, or choosing the alternative that paired a walker with 4 point gait. In both examples, the gait pattern is not ever used with that particular ambulation aid.

\section{Retention.}

One 5-item probe was taken after six weeks. All of the participants but Participant 2 had lower probe scores on the follow-up test than they had at the conclusion of instruction.

Retention scores were lower than expected for Participants 1, 3, 4, 6, and 7 because they had answered items correctly 6 to 12 times in a row by the end of instruction, but answered them incorrectly on the follow-up test. 
Although most of the participants had lower scores at follow-up than at the end of instruction, more than half had higher follow-up scores when compared to baseline. Five participants (P 2, 3, 4, 5, \& 9) had follow-up scores that were higher than baseline, one participant (P 8) had the same score, and three (P 1, 6, \& 7) had lower scores.

Responses for the follow-up probe items were analyzed to determine sources of error. Most of the errors (seven) were related to choosing the appropriate ambulation aid for a patient's problem (Module 6). Choosing a cane for a non-weight bearing patient was a common error. Linking the wrong gait pattern to an ambulation aid, such as 4 point gait for a walker, accounted for five errors (Module 3). Choosing the incorrect gait pattern for a patient's problem, like a 2 point gait for non-weight bearing, also accounted for five errors (Module 5). Two errors were related to choosing a more restrictive gait pattern, such as 4 point, instead of the least restrictive 2 point gait pattern (Module 4), and two errors were related to choosing less restrictive ambulation aids such as crutches instead of a walker (Module 2).

\section{Fluency and Persistent Errors}

Most of the errors that persisted or reappeared at follow-up were related to three specific instructional modules: gait patterns to be used with each ambulation aid (Module 3); patient problems and gait patterns (Module 5); patient problems and ambulation aids (Module 6). None of the participants who made errors related to Module 3 (Participants 1, 4, 5, 7, \& 8) achieved fluency for Quiz 3. Similarly, none of the participants who made errors related to Module 5 (Participants 4, 7, 8, \& 9) achieved fluency for the relevant quiz. Contrary to these findings, all of the participants who made errors related to Module 6 (Participants 3, 4, 5, 6, 8, 9) achieved fluency for the associated quiz except for Participant 6. Of the remaining errors on the follow-up test, fluency for Module 4 was obtained by 2 of the 3 participants who made errors (P 6, 7). Participant 6 made the only error related to Module 2 in spite of having fluency on the relevant quiz. 


\section{Summary}

Physical therapist assistant students used text readings and quizzes to learn gait training theory in order to choose ambulation aids and gait patterns for patients in described clinical scenarios. Learning component skills led to better performance of the higher level skill for all but one of the students. The learning task was mastered by 3 participants: one after 4 pretests; one after standard quiz instruction (although probe stability was not obtained); one after standard quiz instruction and fluency training. A fourth participant had a perfect 5 out of 5 follow-up score.

Specific instruction in a problem solving strategy led to further learning gains after fluency training for 5 out of 6 participants. However, instruction in the steps to follow to reach a decision did not compensate for a lack of factual knowledge and participants persisted in making factual errors.

After six weeks, all of the participants but one had lower probe scores. However, five out of nine participants retained more gait training skill than they had demonstrated during baseline. When specific responses to items were analyzed, three of the component knowledge areas (Modules 3, 5, \& 6) accounted for 17 out of 21 factual errors on the follow-up probes. Students had not demonstrated quiz fluency for 2 out of 3 of the related component knowledge quizzes for which errors persisted. Fluency in these three quizzes was positively related to final probe performance showing that fluency is critical for higher level problem solving. 


\section{Chapter 4. Discussion}

This study investigated whether learning component facts and theory related to gait training would result in better skill at choosing gait patterns and ambulation aids for patients in described clinical scenarios. The skill of choosing gait training details was evaluated through the responses that participants made to multiple-choice questions. They learned the component information by reading short text passages and taking quizzes composed of multiple-choice and fill-in items. The participants were divided into two groups so that the learning achieved through reading text passages and taking quizzes could be contrasted with the learning that resulted from reading the same text passages and retaking the quizzes until predetermined accuracy aims were achieved. It was anticipated that the participants would repeat the quizzes several times so that the time needed to complete a quiz repetition would decrease and they would become fluent in the component knowledge. Although the actual difference in the number of quiz repetitions between the groups was small, an important relationship was found between fluency in three critical component skills and the probe score at the end of instruction.

\section{Component/Composite Effect}

Choosing an appropriate ambulation aid and gait pattern for a patient to use that will ameliorate a walking problem with minimal interference with other daily functions requires a high level of clinical problem solving. The participants in this study developed greater skill at performing the complex task just by learning component factual information. For all of the participants but one, prior knowledge of gait training was limited to what could be gained through typical lay person experience. Participants learned the vocabulary and theory associated with gait training by working through the instructional materials, and as a result, they developed skill in choosing the correct ambulation aid and gait pattern from a list of alternatives. The participants did not receive feedback for individual responses to the application probe items so it is likely that improvement in probe scores resulted from the instructional materials rather than from memorizing answers for probe items.

Although all of the participants completed the study in less than three hours, the amount of time that they spent interacting with the instructional materials varied a great deal. Those who completed both the standard quiz instruction and fluency training generally spent more time 
studying than those who completed only one instructional sequence, but instructional time was not correlated with learning. Because the participants could stop instruction when they mastered the learning task, those who learned quickly or possessed greater incoming knowledge finished first. The self-paced activities allowed each participant to spend as much time as needed to complete the task.

\section{Identification of Critical Components}

The instructional modules were designed to contain all of the information needed to solve the clinical problems and they were organized so that all related information for each subskill was contained in one module. The modules were sequenced to enhance understanding. For example, participants learned the names of the gait patterns to use with each ambulation aid before they learned which gait patterns were least and most restrictive. Three of the modules (Modules 3, 5, \& 6) were critical for performing the higher level skill because 81 percent of the problem solving errors that appeared on the follow-up probe resulted from factual errors in those knowledge areas, and achieving fluency in those modules was positively correlated with probe scores. All of the modules were composed of the same instructional materials (readings and quizzes or fluency training), but the format may not have been equally effective for all of the content areas. The same fluency criteria, in particular, may not have been appropriate for the content of the different modules. If component tasks are critical for success at solving higher level problems, then care should be taken to identify the necessary criteria to ensure learning at a sufficient level for later success. Further discussion of persistent errors is presented below.

\section{Problem Solving Strategy Effect}

Most of the participants who received the problem solving strategy made further learning gains. The strategy listed the steps to use to apply the component knowledge so that the most important decisions were made first. For example, eliminating the alternatives that were not appropriate for the patient's weight bearing status was the first step. Although the strategy led to better performance of the problem solving task, it did not compensate for faulty factual knowledge. Participants who had not learned that a cane is never used for a non-weight bearing 
gait persisted in choosing a cane as the appropriate ambulation aid for a patient when they were asked to choose the least restrictive alternative. Even though a cane is least restrictive, a person cannot safely use one to transfer body weight from a fractured hip.

The problem solving strategy was given to the participants as a final attempt to help them gain mastery of the leaning task. It may be more instructionally sound to give students a strategy as the first step in an instructional sequence. Instruction in how the facts are to be used might increase motivation as well as provide a method for applying the facts as they are learned.

The participants in this study probably would have learned to answer the probe questions correctly if they had received feedback about the correctness of their responses for each question. However, if choosing ambulation aids and gait patterns for patients were only taught with application probes, students might memorize specific examples rather than learn to respond to the principles taught. Items to address every possible clinical situation would have to be developed for students to be adequately prepared to handle novel situations. Designing instructional contingencies to ensure that students develop an adequate foundation of component knowledge is more efficient than practicing problem solving alone because students would be prepared for all of the possible combinations of patient conditions.

\section{Faulty Factual Knowledge}

Although the participants in this study improved in the skill of choosing ambulation aids and gait patterns, they did not master the task because they did not develop an adequate foundation of component knowledge. Several possible reasons are proposed and will be discussed along with suggestions for changes in the instructional design.

Student Motivation. Physical therapist assistant students were required to participate in this study because the information that was taught was established curricular content commonly taught in the semester in which the study was conducted. Human subject safeguards allowed them to complete the activities anonymously and they received homework points only for participation, regardless of the effort or score that they made. Anonymity also assured them that they would not be held accountable for their performance. Because they made fewer numbers of quiz repetitions in this study and earned fewer points than they did for an earlier classroom 
assignment, it appears that they may not have been motivated to work as hard or as long to achieve more than the minimum required for progression through the modules.

The earlier classroom assignment that was used as a comparison for repetitions and points, in contrast to this study, was completed over a period of weeks and students could work in multiple sessions. Since they were required to work continuously for a three hour block during this study, they may have been more concerned with finishing than with learning. If instructional materials such as the ones used in this study are intended to be a supplement to regular classroom activities, it may be more helpful to study their effectiveness in the manner in which they are likely to be used. Real academic contingencies, such as allowing the students to work at their own pace over a period of weeks, and having scores reviewed by an instructor, may have resulted in better motivation to repeat the quizzes and gain mastery of the factual knowledge. In any case, the instructional design should have established better contingencies to ensure that the participants worked long enough to learn the foundation gait training knowledge.

Quiz Repetitions. One contingency that might have resulted in more learning would have been to require a set number of quiz repetitions. Although participants did not receive feedback about individual probe items, they did receive feedback for individual quiz items: the quizzes provided the opportunity for students to make active responses and receive immediate feedback. Because the 10-item quizzes were randomly drawn from a pool of at least 24 items, the participants were only given feedback for responding to all of the 24 items if they repeated a quiz multiple times. Consequently, participants who completed one quiz repetition per module had to rely on the facts they remembered from studying the text passages. The software could have been programmed so that they could not progress through the modules without meeting repetition requirements, thus ensuring adequate active responding. The number of quizzes or the number of items in each quiz could also have been increased so that every item was included in a quiz and would require an active response.

Fluency Requirement. The effects of fluency were not fully established in this study. Because the participants were held to only accuracy standards and not time standards during fluency training, they reached fluency on only half of the six quizzes. The software could have been programmed to stop a quiz when the time limit was reached so a participant would have to 
meet the fluency criteria to continue with the instructional sequence. As a result, all of the students would have achieved fluency and may have shown greater gains in problem solving skill.

Enforcing fluency aims would also have resulted in more quiz repetitions for many of the quizzes with the corresponding benefit of more active responses and feedback for more quiz items. However, reaching fluency standards for time and accuracy might have been more important for mastery than quiz repetitions alone because a lack of fluency was associated with persistent errors. More than half of the participants (52\%) who made errors on the follow-up probe had not achieved fluency on the related quiz. Three of the modules were found to be critical for learning because fluency on those quizzes was correlated with higher probe scores.

Errors related to Module 6 were the most common in the follow-up probe even though 5 out of 6 participants achieved quiz fluency. The quiz items were primarily multiple-choice and the participant had to choose the appropriate ambulation aid for a stated patient problem. For example, when asked to choose an ambulation aid for a patient who is non-weight bearing, the alternatives included cane, crutches, walker, both, and all of the above in different combinations. Fill-in questions were also used so that the participant had to type either walker or crutches, but there were fewer of them than multiple-choice items. Consequently, the items could be answered and a quiz completed very quickly. The instructor who developed the quiz could score 10 out 10 correct in 53 seconds without practice, so a fluency criterion of 2 minutes or less was probably too lenient for mastery. Fluency aims should be set individually for each quiz so that mastery and transfer are more likely to occur.

\section{Retention}

More than half of the 9 participants retained some of the skill at choosing ambulation aids and gait patterns that they gained through instruction in the component facts, but almost none maintained the performance level that they demonstrated at the conclusion of instruction. Only participant (P 2) demonstrated as much as or more skill at follow-up than had been evident during instruction. Since students must pass a licensing examination after graduation in order to work as physical therapist assistants, retention of the skills learned in the program is critical to 
future success. Learning activities should be effective both for acquisition of knowledge and skills and for retention. The instructional design used in this study, especially the failure to restrict progression if fluency criteria were not met, may have resulted in less retention than desired. The design of the probes may also have interfered with retention and will be discussed further. The anonymity required for human subjects protection may also have caused the participants to be less motivated and less careful when responding to probe items than when in normal class circumstances, so the follow-up scores may not reflect true retention.

Lack of Fluency. Fluency is associated with retention and the fact that participants achieved fluency on only half of the quizzes may have led to lower follow-up scores. Fluency at the 2 minute level may have been insufficient for some of the quizzes because aims were set without comparison to what could be obtained by someone already skilled in the target behavior. The participant (P 1) who achieved mastery during baseline and continued to have perfect 5 out of 5 probe scores for the six modules in standard quiz instruction, made the same error on the follow-up probe as was made on the first two pretests. Participant 1 did not receive fluency training but may have avoided the identical error at follow-up if fluency had been obtained for the relevant quiz.

Student Motivation. Participant motivation and the lack of accountability may also be a factor in follow-up probe performance. Errors appeared in follow-up that had seldom or never been made by a participant in the preceding probes. For example, Participants 3 and 6 made errors on the follow-up probe that they had not made on 11 and 12 preceding probes respectively. This fact is especially remarkable for Participant 3 because probe mastery was achieved at the end of standard quiz instruction, but score stability was not obtained and fluency training was also given. Participant 3 answered all of the probe items correctly six times during fluency training but did not did not demonstrate mastery six weeks later.

Use of Patient Names. The participants may have been motivated to perform well on the follow-up probe but found they were expected to recall information that they did not know they were supposed to learn. In the probes, the patients used for examples were given fictitious names to form paired items that appeared to be different but required identical gait training knowledge to solve. Participants may have used age and gender cues from the names to make 
inappropriate decisions. They were also likely to remember that Mrs. Smith used a walker with a 3 point gait and not remember that she used it because it was the most restrictive aid for a person who is non-weight bearing on one lower extremity. The names were removed from the followup probe so that retention of gait training knowledge could be tested rather than retention for a specific patient's gait training need. Participant 2, who had low probe scores at the end of instruction ( 2 out of 5) and made persistent errors in the final probes in spite of having achieved fluency on the relevant quizzes, had a perfect score on the follow-up probe. Without the patients' names to influence recall, it is possible that the participant responded to specific gait training stimuli. Conversely, Participant 3 made an error in follow-up that had not been made in the previous 11 probes, in spite of having fluency in the relevant quiz. This participant may have been receiving feedback for linking an alternative with a patient's name, rather than with the appropriate weight bearing status. The fictitious patient names may also have been responsible for the decrease in probe scores during instruction and the low follow-up score (0 out of 5) for Participant 6 if attention was given to individual names rather than relevant gait training information.

Although it is important to test students according to how they are instructed, it is more important to construct the instructional materials so that they learn to get the correct answers by responding to the appropriate stimuli. The application probe items should have had a different patient name every time the item appeared in a test, or they should have been phrased like the follow-up probe items without any names at all.

\section{Limitations of Study}

Threats to internal validity were well controlled in this study. Because the data were gathered during one training session and participants began instruction after varying numbers of baseline assessments, history, maturation, and attrition were not limiting factors. Requiring stable probe scores before instruction began or changed helped control the effects of repeated testing and statistical regression. Furthermore, the computer scored the items and recorded the data, so there was little threat to interval validity because of instrumentation effects. Therefore, 
the learning that occurred during the study is likely to have resulted from the instructional activities.

The primary research question of whether PTA students could learn to choose ambulation aids and gait patterns by practicing only the component skills was answered affirmatively. However, mastery and retention of the higher level skill did not reach satisfactory levels for all students. The instructional design failed to employ adequate contingencies to ensure that students practiced the quiz items enough to master the component skills. Strictly held fluency aims and the opportunity to practice all of the quiz items may have resulted in better learning and fewer factual errors.

Strictly held fluency aims would also have allowed more information to be gained about the effect of fluency on solving novel problems and on retention. The quiz scores indicated that the participants knew over 80 percent of the factual knowledge, but accuracy alone was not sufficient for higher level skill performance and retention.

Allowing the students to participate anonymously may also have limited learning because they were rewarded for participating, regardless of how much they learned or retained. The lack of accountability and potential for decreased motivation limits the utility of the study for predicting how much learning would occur in actual class assignments.

\section{Suggestion for Future Research}

This study shows that students can develop higher level skills through the practice of component skills, but future research is needed to address the identified limitations. Most importantly, the instructional design should hold students to strict fluency requirements. The most effective fluency aims could be established by comparing the effects of different accuracy levels, such as 100 or 90 percent, as well as different time restrictions on application and retention.

The quizzes should also be designed so that students have the opportunity to answer all of the items that teach important facts. However, if the time required to work through the quizzes is too great, students may need multiple learning sessions. Letting the students work outside of class time over a number of weeks would control for fatigue and boredom and would test the 
effects of the computer-based advantage of any time, any place instruction. Time and sequence restrictions could be programmed into the software to partially substitute for the control offered in a monitored computer lab. As in this study, progression to a new quiz could be dependent on satisfying the criteria for the preceding quiz.

Analysis of individual probe responses suggested that the participants may have used age and gender cues from the fictitious patient names to choose probe response alternatives. They may also have remembered the name rather than the patient condition associated with a response alternative so that they did not attend appropriately to the stimuli that could be generalized to other patients. Using application probes without patient names throughout the study should be tested to see if there is a different effect on learning and retention.

The research design in this study required the participants to answer the same 5 item probe pairs at least 16 times. Although they received feedback as to how many of the items they answered correctly, they did not receive feedback about the correctness of individual responses. It is aversive to continue to get low scores without knowing how to correct errors and this aspect of the study design may have decreased motivation. To eliminate this problem, more participants could be used so that fewer probes would be necessary. A probe at the end of each

phase rather than at the end of each module would be sufficient to test the learning that occurred, and replication across participants would make it possible to generalize the study results.

\section{Conclusion}

Successful rehabilitation after illness or injury can mean the difference between continuing to live at home and moving to an institution. As the Baby Boomers reach retirement age, the number of people who need rehabilitation services will increase because older people are more likely to have the chronic medical conditions that cause disabling conditions. Physical therapist assistants are part of the rehabilitation team and the demand for trained assistants is expected to grow along with the aging population.

A physical therapist assistant education program spans two short years. Graduates must emerge with a solid foundation of the facts and principles that they need to solve complex clinical problems. Students enter PTA programs with diverse educational backgrounds and need 
different amounts of instructional time to achieve learning goals. The challenge for program faculty is to design instructional materials that are efficient and effective so all students can gain the skills they need to provide quality care and pass the licensing examination to join the work force.

The learning effects demonstrated in this study suggest that computer-based practice of component skills is an efficient way to facilitate problem solving performance. Most of the students gained skill in choosing ambulation aids and gait patterns for patients by learning foundation gait training facts and principles. Whereas learning subskills resulted in improved problem solving ability, instruction in a problem solving strategy did not compensate for faulty foundation knowledge. When students learned the critical information to fluency, problem solving performance was enhanced.

Computer-based learning activities have the advantage of being available outside of traditional class time so that students can work at an individual pace until mastery is achieved. Contingencies can be programmed into the software so students progress through the materials in the optimum order and receive feedback for learning. In this way, students who enter PTA programs are more likely to graduate with the skills they need to be successful as physical therapist assistants. 


\section{References}

American Physical Therapy Association (1999). A Normative Model of Physical Therapist Assistant Education, Version 99.

Barlow, D., \& Hensen, M. (1984). Single Case Experimental Designs: Strategies for Studying Behavior Change (2nd ed.). New York: Pergamon Press, Inc.

Barnes, D. (1994). Stimulus equivalence and relational frame theory. The Psychological Record, 44, 91-124.

Berninger, V. W., Vaughan, K., Abbott, R. D., Begay, K., Coleman, K. B., Curtin, G., et al. (2002). Teaching spelling and composition alone and together: Implications for the simple view of writing. Journal of Educational Psychology, 94, 291-304.

Binder, C. (1996). Behavioral fluency: Evolution of a new paradigm. The Behavior Analyst, 19, 163-197.

Bucklin, B. R., Dickinson, A. M., \& Brethower, D. M. (2000). Comparison of the effects of fluency training and accuracy training on application and retention. Performance Improvement Quarterly 13(3), 140-163.

Bukowski, E. L. (2002). Assessment outcomes: Computerized instruction in a human gross anatomy course. Journal of Allied Health, 31, 153-158.

Chard, D. J., Vaughn, S., \& Tyler, B.-J., (2002). A synthesis of research on effective interventions for building reading fluency with elementary students with learning disabilities. Journal of Learning Disabilities, 35, 386-406.

Clariana, R. B. (1990). A comparison of answer until correct feedback and knowledge of correct response feedback under two conditions of contextualization. Journal of ComputerBased Instruction, 17(4), 125-129.

Clariana, R. B. (1993). The effects of item organization and feedback density using computerassisted multiple-choice questions as instruction. Journal of Computer-Based Instruction, 20(1), 26-31.

Clariana, R. B., \& Lee, D. (2001). The effects of recognition and recall study tasks with feedback in a computer-based vocabulary lesson. Educational Technology Research and Development, 49(3), 23-36.

Clayton, M. C., \& Hayes, L. J. (1999). Conceptual differences in the analysis of stimulus equivalence. The Psychological Record, 49, 145-161. 
Crooks, S. M., Klein, J. D., Savenye, W., \& Leader, L. (1998). Effects of cooperative and individual learning during learner-controlled computer-based instruction. Journal of Experimental Education [Online], 66(3), 223. Available: InfoTrac/Expanded Academic ASAP/A20550043 [2000, March 17].

Dempsey, J. V., Litchfield, B. C. (1993). Feedback, retention, discrimination error, and feedback study time. Journal of Research on Computing in Education, 25, 303-326.

Driskell, J. E., Willis, R. P., \& Copper, C. (1992). Effect of overlearning on retention. Journal of Applied Psychology, 77, 615-622.

Duarte, A. M., Eikeseth, S., Rosales-Ruiz, J., \& Baer, D. M. (1998). The effects of a can't answer response option and instructions on stimulus equivalence. The Psychological Record, 631-646.

Eikeseth, S., Rosales-Ruiz, J., Duarte, A., \& Baer, D. M. (1997). The quick development of equivalence classes in a paper-and-pencil format through written instructions. The Psychological Record, 47, 275-284.

Eniaiyeju, P. A. (1983). The comparative effects of teacher-demonstration and self-paced instruction on concept acquisition and problem-solving skills of college level chemistry students. Journal of Research in Science Teaching, 20, 798-801.

Evans, M. (1997). Bright ideas: Integrating art criticism. School Arts [Online], 96(8), 48. Available: InfoTrac/Expanded Academic ASAP/A19274752 [2000, April 28].

Foorman, B. R., Torgesen, J. (2001). Critical elements of classroom and small-group instruction promote reading success in all children. Learning Disabilities Research \& Practice, 16, 203-212.

Gagne', E. D., Crutcher, R. J., Anzelc, J., Geisman, C., Hoffman, V. D., Schutz, P. et al. (1987). The role of student processing of feedback in classroom achievement. Cognition and Instruction, 4, 167-186.

Green, G., Stromer, R., \& Mackay, H. A. (1993). Relational learning in stimulus sequences. The Psychological Record, 43, 599-616.

Harrington, M. J. (1996). Basic instruction in word analysis skills to improve spelling competence. Education, 117, 22. Available: InfoTrac/Expanded Academic ASAP/A18960214 [2003, January 3].

Hazlett, K. H. (1999). Effects of cumulative practice on mathematics problem-solving behavior (Doctoral dissertation, West Virginia University, 1999). Dissertation Abstracts International, 10b, 5545. 
Hoenig, H., Rubenstein, L. V., Sloane, R., Horner, R. \& Kahn, K. (1997). What is the role of timing in the surgical and rehabilitative care of community-dwelling older persons with acute hip fracture? Archives of Internal Medicine, 157 (5), 513. Available: InfoTrac/Expanded Academic ASAP/A19203174 [2002, November 22].

Hoffman, J. V., \& Isaacs, M. E. (1991). Developing fluency through restructuring the task of guided oral reading. Theory Into Practice, $X X X, 185-194$.

Innis, A., Lane, S. D., Miller E. R., \& Critchfield, T. S. (1998). Stimulus equivalence: Effects of a default-response option on emergence of untrained stimulus relations. Journal of the Experimental Analysis of Behavior, 70, 87-102.

Ivarie, J. J. (1986). Effects of proficiency rates on later performance of a recall and writing behavior. Remedial and Special Education, 7, 25-30.

Johnson, K. R. (1997). Morningside Academy. Behavior and Social Issues, 7, 31-35.

Johnson, K. R. \& Layng, T. V. (1992). Breaking the structuralist barrier: literacy and numeracy with fluency. American Psychologist, 47, 1475-1490.

Katayama, A. D., \& Robinson, D. H. (2000). Getting students "partially" involved in notetaking using graphic organizers. The Journal of Experimental Education, 68, 119-133.

Kazdin, A. E. (1982). Single-Case Research Designs: Methods for Clinical and Applied Settings. Oxford University Press.

Kelly, G., \& Crosbie, J. (1997). Immediate and delayed effects of imposed postfeedback delays in computerized programmed instruction. Psychological Record, 47, 687-698.

Kirby, J., Machlin, S. \& Thorpe, J. (2001). Patterns of Ambulatory Care. Rockville, Md.: Agency for Healthcare Research and Quality, Pub. No. 01-0026.

Kritch, K. M. \& Bostow, D. E. (1998). Degree of constructed-response interaction in computerbased programmed instruction. Journal of Applied Behavior Analysis, 31, 387-398.

Kulik, J. A. \& Kulik, C. C. (1988). Timing of feedback and verbal learning. Review of Educational Research, 58, 79-97.

Levy, B. A., Abello, B., \& Lysynchuk, L. (1997). Transfer from word training to reading in context: Gains in reading fluency and comprehension. Learning Disability Quarterly, 20, 173-188.

Meyer, M. S., \& Felton, R. H. (1999). Repeated reading to enhance fluency: Old approaches and new directions. Annals of Dyslexia, 49, 283-306. 
Meyer, M. S., Wood, F.B., Hart, L. A., \& Felton, R. H. (1998). Selective predictive value of rapid automatized naming in poor readers. Journal of Learning Disabilities, 31, 106-117.

Ormrod, J. E., \& Spivey, N. R. (1990). Overlearning and speeded practice in spelling instruction. Psychological Reports, 67, 365-366.

Rasinski, T. V. (1990). Effects of repeated reading and listening-while-reading on reading fluency. Journal of Educational Research, 83(3), 147-150.

Rehfeldt, R. A., Dixon, M. R., Hayes, L. J., \& Steele, A. (1998). Stimulus equivalence and the blocking effect. The Psychological Record, 48, 647-664.

Rehfeldt, R. A., \& Hayes, L. J. (2000). The long-term retention of generalized equivalence classes. The Psychological Record, 50, 405-428.

Schroth, M. L. (1995). Variable delay of feedback procedures and subsequent concept formation transfer. The Journal of General Psychology, 122, 393-399.

Schroth, M. L. (1997). The effects of different training conditions on transfer in concept formation. The Journal of General Psychology, 124, 157-165.

Shepard, K. F., Jensen, G.M., \& Hislop, H. J. (1990). Physical therapist curricula for the 1990s: Educating the reflective practitioner. Physical Therapy, 70, 566-577.

Sidman, M. (1960). Tactics of Scientific Research. New York: Basic Books, Inc.

Skinner, B. F. (1953). Science and Human Behavior. The Macmillian Company.

Slaughter, D. S., Brown, D. S., Gardner, D. L., \& Perritt, L. J. (1989). Improving physical therapy students' clinical problem-solving skills: An analytical questioning model. Physical Therapy, 69, 441. Available: InfoTrac/Expanded Academic ASAP/A7666383 [2003, January 3].

Stayter, F. Z., \& Allington, R. L. (1991). Fluency and the understanding of texts. Theory Into Practice, $X X X, 143-148$.

U.S. Census Bureau (2000). Projections of the Total Resident Population by Five-Year Age Groups. Washington: Census Bureau, Population Projections Program.

Vaughn, S., Chard, D .J., Bryant, D. P., Coleman, M., Tyler, B.-J., Linan-Thompson S. et al. (2000). Fluency and comprehension interventions for third-grade students. Remedial and Special Education, 21, 325-335. 
Waldrop, P. B. (1984). Behavior reinforcement strategies for computer-assisted instruction: Programming for success. Educational Technology, 24(9), 34-41.

Washburn, D. A. (1999). Distinguishing interpretation from fact (DIFF): A computerized drill for methodology courses. Behavior Research Methods, Instruments, \& Computers, 31, 36.

White, J. A., Breit, F. (1994). Effects of aptitude and corrective feedback on performance in computer-directed mathematics. Journal of Research on Computing in Education, 26(4), 475-487.

White, W. F. (1993). From S-R to S-O-R: What every teacher should know. Education, 113, 620-629.

Williams, B. O., Dwyer, F. M. (1996). Interactive effects of mixed-chunk elaboration feedback in facilitating student achievement. International Journal of Instructional Media, 23, 245-255.

Yaber, G. E. \& Malott, R. W. (1993). Computer-based fluency training: A resource for higher education. Education \& Treatment of Children, 16, 306-315. 


\section{Appendix A. Computer Lab Floor Plan}

Teacher's Table

\begin{tabular}{|l|l|l|l|}
\hline Work Statiфns 1-4 & & \\
& & & \\
\hline
\end{tabular}

\begin{tabular}{|l|l|l|}
\hline Work Statiфns 13-15 & \\
& & \\
\hline
\end{tabular}

\begin{tabular}{|l|l|l|l|}
\hline Work Stations 5-8 & & \\
& & & \\
\hline
\end{tabular}

Work Stations 16-18

\begin{tabular}{|l|l|l|l|}
\hline Work Stations 8-12 & & \\
& & & \\
\hline
\end{tabular}

Work Stations 19-20 


\section{Appendix B. Instructor Procedure}

Getting Started. Give each student a pink envelope. The user name and password for the activity is inside. Give each student a Pretest Instruction Sheet. Instruct students to open envelope, log onto WebCT, and begin.

Pretest Procedure. Students complete the pretest three times and bring the scores to you when they are finished. Verify the scores in WebCT. Check the scores for stability. Stability is defined as 2 scores at same or declining level. Tell students to repeat pretest as needed to meet stability criteria. Have some students repeat more times even if stable to meet multiple baseline criteria. Some students should do the pretest 4 or 5 times just so they don't all start after 3 pretests. Assign Quizzes or Drills intervention by giving the student the handout for the first assignment. The password for the first activity is on the handout. Half the students start with Quizzes and half start with Drills. Match them according to the pattern of the number of items they answer correctly during the baseline phase. For example, a student who scores 0-1-0 will be matched with a similarly scoring student but not with one who scores 1-1-2-1.

\begin{tabular}{|ll|ll|}
\hline \multicolumn{1}{|c|}{ Quiz } & \multicolumn{1}{c|}{ Drill } \\
\hline Student & Scores & Student & Scores \\
\hline Student & Scores & Student & Scores \\
\hline Student & Scores & Student & Scores \\
\hline Student & Scores & Student & Scores \\
\hline Student & Scores & Student & Scores \\
\hline
\end{tabular}

First Round. Students work through assigned intervention. WebCT restricts access as required. They will bring scores to you when finished with the last test. Check scores for stability (no upward trend across last 3 attempts). Have students repeat last Application test as needed to show stability.

Reassignment. Students who have stable 5/5 performance on the Application Test are finished and they can leave. Students who do not show mastery have further instruction. Give them the handout for the next activity.

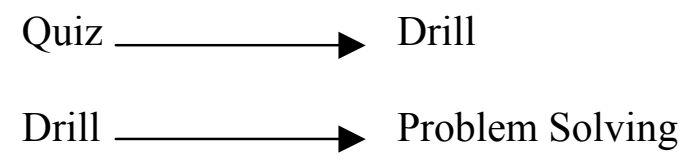

Second Round. Students work through Drill Intervention and bring scores to you when finished. Instruct them to repeat Application Test if needed for stability. Students who are assigned to use the problem solving strategy bring final test score to you. Check for stability. Look at the last two Application Test scores from the Drill Intervention and the final score they bring you. They have to repeat the last test until scores are stable (no upward trend across last 3 attempts). 
Reassignment. Students who used the problem solving strategy are finished. Students who have stable $5 / 5$ performance on the Application Test are finished. Students who do not show mastery are given the problem solving strategy.

$$
\text { Drill } \longrightarrow \text { Problem Solving (give handout and release module) }
$$

Third Round. Assigned students use the problem solving strategy and bring final score to you. Check for stability as before.

Reassignment. All students are finished at this time. Retention test is given 6 weeks later. Remind them not to talk about the test questions or read their books until after this last test.

Stability Criteria for Pretest: 2 scores at same or declining level.
1. $\mathrm{X} \quad \mathrm{X}$
2. $\mathrm{X}$
$\mathrm{X}$

Stability Criteria: no upward trend across last 3 attempts.
1. $\mathrm{X} \quad \mathrm{X} \quad \mathrm{X}$
2. $\mathrm{X}$
X $\quad X$

3. $\mathrm{X} \quad \mathrm{X}$

$\mathrm{X}$

4.

$\mathrm{X} \quad \mathrm{X}$

5. $\quad$ X $\quad X \quad X$ 


\section{Appendix C. Student Instructions}

\section{Pretest Instructions}

General Directions. You are going to work through a series of activities to (1) teach you about gait training and (2) provide data for Beverly Born's doctoral dissertation. You will not always be doing the same things as your classmates because the purpose of the research is to see which combination of activities works best. Please don't discuss this project with each other or read about gait training in any of your text books. Dr. Susan Goodwin will answer your questions during the time you are here.

Benefits. The short-term benefits are that you will earn homework points as part of the course requirements for PTA 102 and she will finish a degree she has been working on since 1997. The long-term benefit is that she will know more about designing instructional activities to help future PTA students learn.

Risks. There are no risks to you. Your name will never be associated with the data, and no one will know how you scored or even if you participated at all. You can refuse to let her use your data, but you are still required to complete these activities today. You will receive the homework points after you finish the activities even if you don't let her use your data.

Log On to WebCT. Log onto WebCT with the user name and password that the instructor gave you. Go to the Test of Learning homepage.

Pretest. Select the Pretest icon then start the pretest quiz. The password is spta. View your scores when you are finished. WebCT won't tell you which ones you answered correctly. Do the pretest a total of 3 times and write your scores here:

Pretest 1

Pretest 2

Pretest 3

Take this sheet to Dr. Goodwin and she will give you further instructions. Don't write in the following spaces unless she tells you to.

Pretest 4

Pretest 5

Pretest 6 


\section{Instructions for Quizzes}

1. Select the Quizzes Icon on the Homepage.

2. Start with the first item and work your way down through all the items. The program will only let you do the activities if you follow the order. The password for Basic Terms Reading 1 is quiz.

3. Look at your scores and the answers after every Reading, Quiz, and Application Test. You won't get the answers for the Application Tests.

4. Record the Application Test Scores here.

Application Test 1

Application Test 2

Application Test 3

Application Test 4

Application Test 5

Application Test 6

5. Take this sheet to Dr. Goodwin when you are finished and she will give you further instructions. Don't write in the following spaces unless she tells you to.

Application Test 6a

Application Test 6b

Application Test 6c 


\section{Instructions for Drills}

1. Select the Drills Icon on the Homepage.

2. Start with the first item and work your way down through all the items. The program will only let you do the activities if you follow the order. The password for Basic Terms Reading 2 is drill.

3. Look at your scores and the answers after every Reading, Quiz, and Application Test. You won't get the answers for the Application Tests. You can repeat the drills because you have to score 9 on each drill to go on in the program.

4. Record the Application Test Scores here.

Application Test 7

Application Test 8

Application Test 9

Application Test 10

Application Test 11

Application Test 12

5. Take this sheet to Dr. Goodwin when you are finished and she will give you further instructions. Don't write in the following spaces unless she tells you to.

Application Test 12a

Application Test $12 \mathrm{~b}$

Application Test 12c 


\section{Instructions for Problem Solving Strategy}

Select the Strategy Icon on the Homepage. The password for Application Test 13 is strategy.

Follow these steps to choose an ambulation aid and gait pattern for the patient described:

1. WEIGHT BEARING STATUS. Eliminate aides that can't be used with the weight bearing status that is described.

2. LEAST OR MOST RESTRICTIVE. From the alternatives left after step 1, eliminate the aids that are more or less restrictive, depending on what the questions asks for.

3. GAIT PATTERN. From the alternatives left after step 2, choose the one with the correct gait pattern.

4. CHECK FOR ERRORS. Can someone with that weight bearing status use the ambulation aid you have chosen? Can the gait pattern be used with that ambulation aid? Is your choice least or most restrictive?

Record your score here: Application Test 13

Take this sheet to Dr. Goodwin when you are finished and she will give you further instructions. Don't write in the following spaces unless she tells you to.

Application Test 13a

Application Test 13b

Application Test 13c 


\section{Appendix D. Scatter Plots of Relationships}

Table E 1. Relationship between the Number of Fluent Quizzes and Final Probe Score

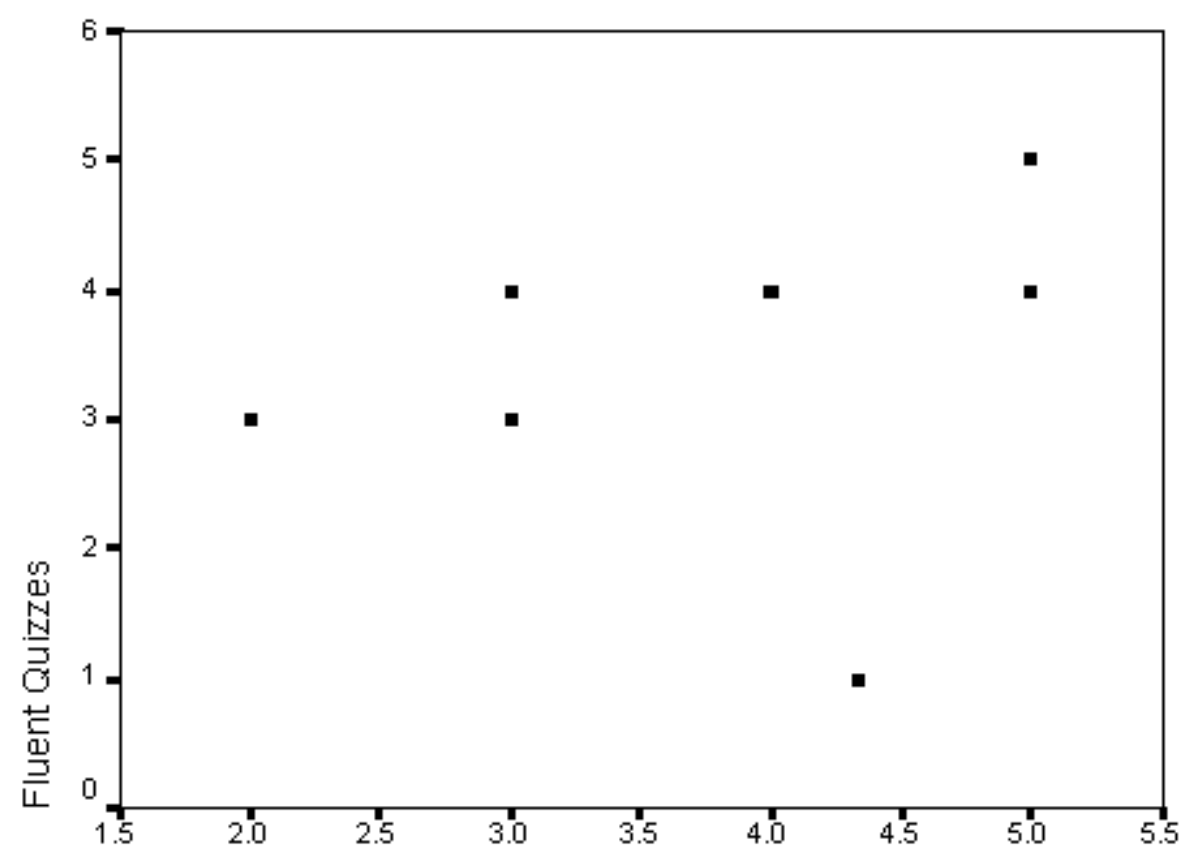

Final Probe Score

Table E 2. Relationship between Fluency on Critical Quizzes and Final Probe Score

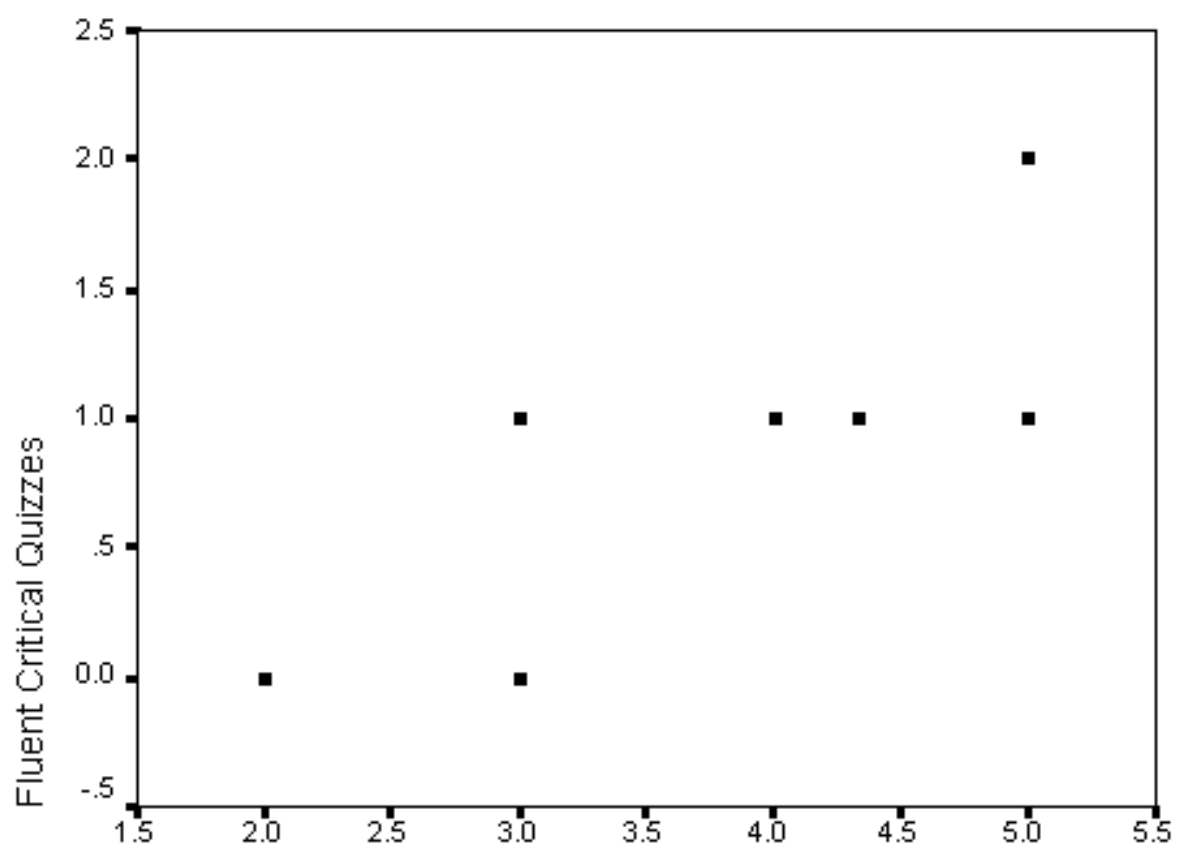

Final Probe Score 
Table E 3. Relationship between Instructional Time and Final Probe Score

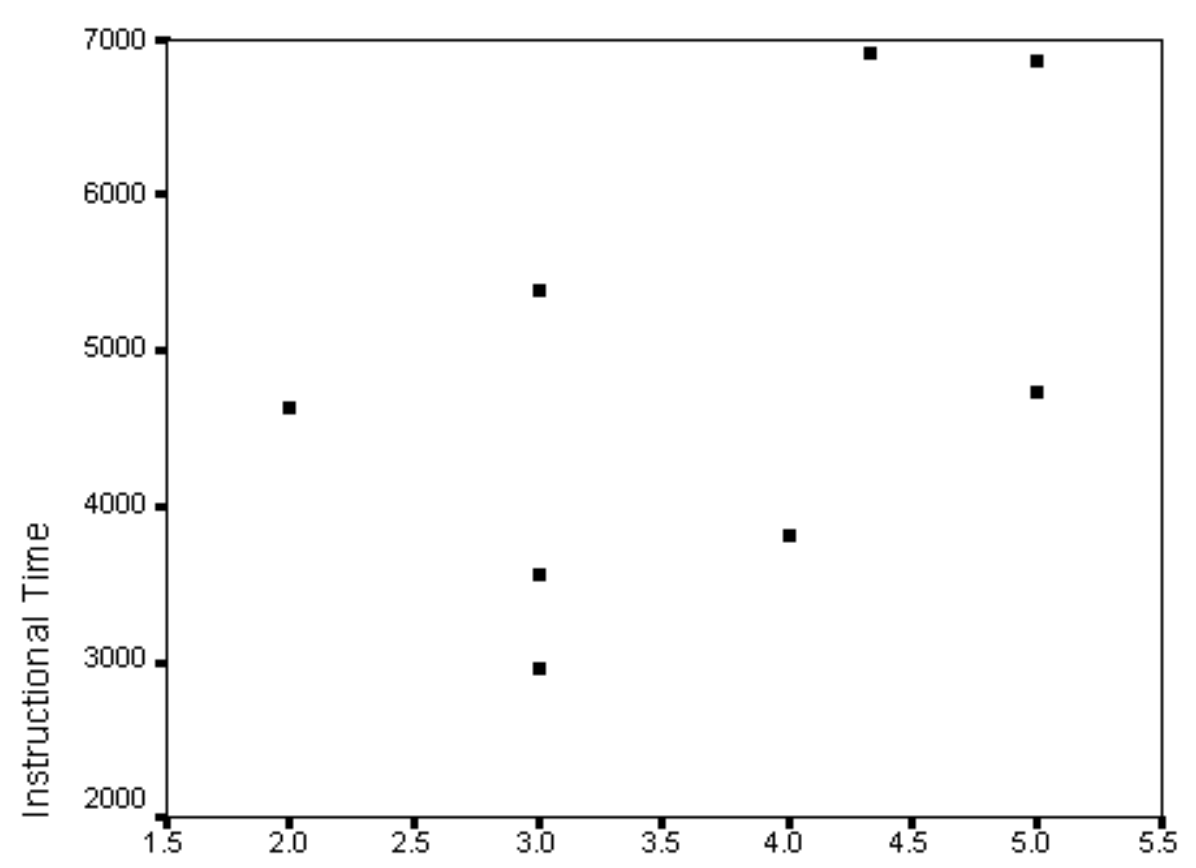

Final Probe Score

Table E 4. Relationship between Number of Quiz Repetitions and Final Probe Score

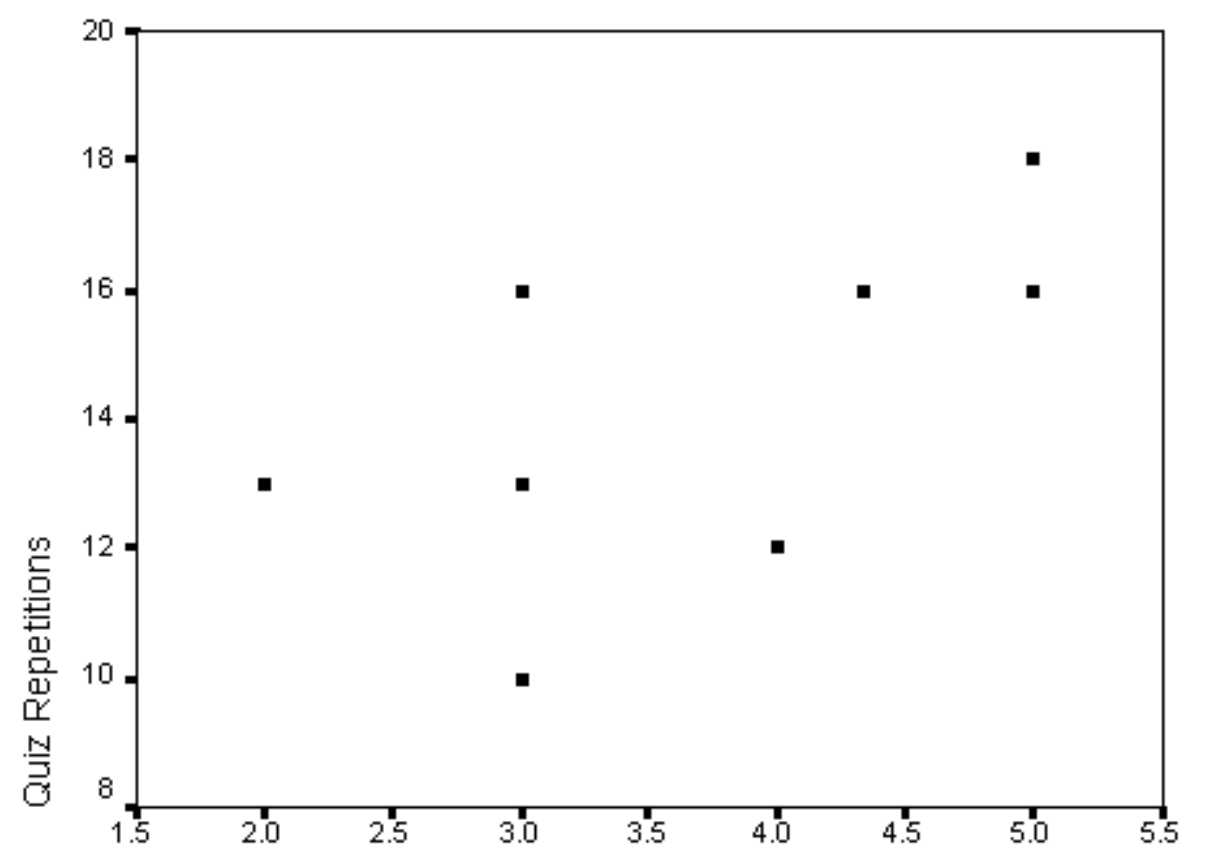

Final Probe Score 


\section{Appendix E. Results for Participant 1}

Participant 1 completed only standard quiz instruction so fluency results are not applicable.

Table 1 Probe Items Answered Correctly for Participant 1

\begin{tabular}{|c|c|c|c|c|c|c|c|c|c|c|c|}
\hline & Probe & Item 1 & Item 1a & Item 2 & Item $2 \mathrm{a}$ & Item 3 & Item $3 \mathrm{a}$ & Item 4 & Item $4 \mathrm{a}$ & Item 5 & Item $5 \mathrm{a}$ \\
\hline \multirow[t]{4}{*}{ Baseline } & Pretest 1 & & $\mathrm{O}$ & & $\mathrm{O}$ & & $\mathrm{X}$ & & $\mathrm{O}$ & $\mathrm{O}$ & \\
\hline & Pretest 2 & & $\mathrm{O}$ & $\mathrm{O}$ & & & X & & $\mathrm{O}$ & $\mathrm{O}$ & \\
\hline & Pretest 3 & $\mathrm{O}$ & & & $\mathrm{O}$ & & $\mathrm{O}$ & $\mathrm{O}$ & & & $\mathrm{O}$ \\
\hline & Pretest 4 & & $\mathrm{O}$ & & $\mathrm{O}$ & $\mathrm{O}$ & & $\mathrm{O}$ & & $\mathrm{O}$ & \\
\hline & & & & & & & & & & & \\
\hline \multirow{3}{*}{$\begin{array}{l}\text { Standard } \\
\text { Quizzes }\end{array}$} & Probe 4 & & $\mathrm{O}$ & & $\mathrm{O}$ & & $\mathrm{O}$ & & $\mathrm{O}$ & & $\mathrm{O}$ \\
\hline & Probe 5 & & $\mathrm{O}$ & $\mathrm{O}$ & & & $\mathrm{O}$ & $\mathrm{O}$ & & & $\mathrm{O}$ \\
\hline & Probe 6 & & $\mathrm{O}$ & $\mathrm{O}$ & & $\mathrm{O}$ & & $\mathrm{O}$ & & $\mathrm{O}$ & \\
\hline Follow-U & & $\Omega$ & & $\Omega$ & & $\mathrm{X}$ & & O & & $\Omega$ & \\
\hline 50110W-U & Probe 14 & 0 & & U & & $x$ & & U & & U & \\
\hline
\end{tabular}

Note. Final 3 probes to show stability at the end of instruction: O correct; X incorrect. Given one item from each pair. 


\section{Appendix F. Results for Participant 2}

Table 1 Quiz Repetitions and Fluency for Participant 2

\begin{tabular}{|l|l|l|l|}
\hline Quiz & $\begin{array}{l}\text { Quiz } \\
\text { Repetitions }\end{array}$ & $\begin{array}{l}2 \text { min } \\
\text { Fluency }\end{array}$ & $\begin{array}{l}\text { Probe } \\
\text { Score }\end{array}$ \\
\hline Basic Terms 2 & 2 & Yes & 1.00 \\
\hline Restrictive Aids 2 & 2 & Yes & 2.00 \\
\hline Gait Pattern 2 & 2 & No & 1.00 \\
\hline Restrictive Gait Pattern 2 & 1 & Yes & 2.00 \\
\hline Impairment and Gait Pattern 2 & 5 & No & 1.00 \\
\hline Impairment and Aids 2 & 1 & No & 2.00 \\
\hline Problem Solving Strategy & & 2.00 \\
\hline Retention Test & & 5.00 \\
\hline
\end{tabular}

Note. Yes indicates the participant scored at least 9/10 correct in 2 minutes or less. The probe score is the number correct out of 5 possible.

Table 2 Probe Items Answered Correctly for Participant 2

\begin{tabular}{|c|c|c|c|c|c|c|c|c|c|c|c|}
\hline & Probe & Item 1 & Item 1a & Item 2 & Item 2a & Item 3 & Item 3a & Item 4 & Item 4a & Item 5 & Item 5a \\
\hline \multirow{6}{*}{ Baseline } & Pretest 1 & & $\mathrm{X}$ & & $\mathrm{X}$ & & $\mathrm{X}$ & & $\mathrm{X}$ & $\mathrm{X}$ & \\
\hline & \begin{tabular}{|l|} 
Pretest 2 \\
\end{tabular} & & $\mathrm{X}$ & & $\mathrm{X}$ & $\mathrm{X}$ & & $\mathrm{X}$ & & $\mathrm{X}$ & \\
\hline & Pretest 3 & & $\mathrm{X}$ & $X$ & & $X$ & & $X$ & & $\mathrm{X}$ & \\
\hline & Pretest 4 & $\mathrm{X}$ & & & $\mathrm{X}$ & $\mathrm{X}$ & & & $\mathrm{X}$ & & $\mathrm{X}$ \\
\hline & Pretest 5 & $X$ & & & $\mathrm{X}$ & & $X$ & & $\mathrm{X}$ & $X$ & \\
\hline & Pretest 6 & & $\mathrm{X}$ & $\mathrm{X}$ & & & $\mathrm{X}$ & & $\mathrm{X}$ & $\mathrm{X}$ & \\
\hline & & & & & & & & & & & \\
\hline \multirow{3}{*}{$\begin{array}{l}\text { Fluency } \\
\text { Training }\end{array}$} & Probe 11 & & $\mathrm{X}$ & & $\mathrm{O}$ & & $\mathrm{X}$ & & $\mathrm{X}$ & $\mathrm{X}$ & \\
\hline & \begin{tabular}{|l} 
Probe $12 \mathrm{a}$ \\
\end{tabular} & & $\mathrm{X}$ & $\mathrm{O}$ & & & $X$ & $\mathrm{O}$ & & & $\mathrm{O}$ \\
\hline & Probe $12 b$ & & $\mathrm{X}$ & & $\mathrm{O}$ & & $\mathrm{X}$ & & $\mathrm{X}$ & & ---- \\
\hline & & & & & & & & & & & \\
\hline \multirow{3}{*}{$\begin{array}{l}\text { Problem } \\
\text { Solving } \\
\text { Strategy }\end{array}$} & Probe 13a & $\mathrm{X}$ & & $\mathrm{O}$ & & & $\mathrm{O}$ & & --- & $\mathrm{X}$ & \\
\hline & Probe 13b & & $\mathrm{X}$ & $\mathrm{O}$ & & & $\mathrm{X}$ & & $\mathrm{O}$ & & $\mathrm{X}$ \\
\hline & Probe 13c & $\mathrm{O}$ & & & $\mathrm{O}$ & $\mathrm{X}$ & & & $\mathrm{X}$ & & $\mathrm{X}$ \\
\hline Follow-Up & Probe 14 & $\mathrm{O}$ & & $\mathrm{O}$ & & $\mathrm{O}$ & & $\mathrm{O}$ & & $\mathrm{O}$ & \\
\hline
\end{tabular}

Note. Final 3 probes to show stability at the end of instruction: O correct; X incorrect. Given one item from each pair. 


\section{Appendix G. Results for Participant 3}

Table 1 Quiz Repetitions and Fluency for Participant 3

\begin{tabular}{|l|l|l|l|}
\hline Quiz & $\begin{array}{l}\text { Quiz } \\
\text { Repetitions }\end{array}$ & $\begin{array}{l}\text { 2 min } \\
\text { Fluency }\end{array}$ & $\begin{array}{l}\text { Probe } \\
\text { Score }\end{array}$ \\
\hline Basic Terms 2 & 2 & Yes & 5.00 \\
\hline Restrictive Aids 2 & 1 & Yes & 5.00 \\
\hline Gait Pattern 2 & 1 & No & 5.00 \\
\hline Restrictive Gait Pattern 2 & 1 & Yes & 5.00 \\
\hline Impairment and Gait Pattern 2 & 4 & Yes & 5.00 \\
\hline Impairment and Aids 2 & 1 & Yes & 5.00 \\
\hline Retention Test & & 4.00 \\
\hline
\end{tabular}

Note. Yes indicates the participant scored at least $9 / 10$ correct in 2 minutes or less or 3 minutes or less. The probe score is the number correct out of 5 possible.

Table 2 Probe Items Answered Correctly for Participant 3

\begin{tabular}{|c|c|c|c|c|c|c|c|c|c|c|c|}
\hline & Probe & Item 1 & Item 1 & Item 2 & Item 2a & Item 3 & Item $3 a$ & Item 4 & Item $4 c$ & Item : & Item 5a \\
\hline \multirow[t]{5}{*}{ Baseline } & Pretest 1 & & $X$ & & $\mathrm{O}$ & & $\mathrm{X}$ & & $\mathrm{X}$ & & $X$ \\
\hline & Pretest 2 & & $\mathrm{O}$ & $\mathrm{X}$ & & $\mathrm{X}$ & & & $\mathrm{X}$ & $\mathrm{X}$ & \\
\hline & Pretest 3 & $\mathrm{X}$ & & & $\mathrm{O}$ & $\mathrm{X}$ & & $X$ & & $\mathrm{O}$ & \\
\hline & Pretest 4 & & $\mathrm{O}$ & $X$ & & $\mathrm{O}$ & & & $\mathrm{X}$ & $\mathrm{O}$ & \\
\hline & Pretest 5 & $\mathrm{X}$ & & & $\mathrm{O}$ & & $\mathrm{X}$ & & $\mathrm{X}$ & & $\mathrm{X}$ \\
\hline \multirow{4}{*}{$\begin{array}{l}\text { Standard } \\
\text { Quizzes }\end{array}$} & Probe 6a & $\mathrm{O}$ & & & $\mathrm{O}$ & & $\mathrm{O}$ & & $\mathrm{O}$ & $\mathrm{O}$ & \\
\hline & Probe $6 \mathrm{~b}$ & $\mathrm{O}$ & & $\mathrm{O}$ & & & $\mathrm{O}$ & & $\mathrm{O}$ & & --- \\
\hline & Probe $6 \mathrm{c}$ & & $\mathrm{O}$ & $\mathrm{O}$ & & $\mathrm{O}$ & & $\mathrm{O}$ & & --- & \\
\hline & Probe $6 \mathrm{~d}$ & & $\mathrm{O}$ & & $\mathrm{O}$ & & $\mathrm{O}$ & & $\mathrm{O}$ & 0 & \\
\hline \multirow{3}{*}{$\begin{array}{l}\text { Fluency } \\
\text { Training }\end{array}$} & Probe 10 & & $\mathrm{O}$ & & $\mathrm{O}$ & $\mathrm{O}$ & & $\mathrm{O}$ & & $\mathrm{O}$ & \\
\hline & Probe 11 & $\mathrm{O}$ & & $\mathrm{O}$ & & & $\mathrm{O}$ & $\mathrm{O}$ & & & $\mathrm{O}$ \\
\hline & Probe 12 & $\mathrm{O}$ & & & $\mathrm{O}$ & $\mathrm{O}$ & & & $\mathrm{O}$ & & $\mathrm{O}$ \\
\hline \multicolumn{2}{|c|}{\begin{tabular}{|l|l|} 
Follow-Up & Probe 14 \\
\end{tabular}} & $\mathrm{X}$ & & $\mathrm{O}$ & & $\mathrm{O}$ & & $\mathrm{O}$ & & $\mathrm{O}$ & \\
\hline
\end{tabular}

Note. Final 3 probes to show stability at the end of instruction: O correct; $\mathrm{X}$ incorrect. Given one item from each pair. 


\section{Appendix H. Results for Participant 4}

Table 1 Quiz Repetitions and Fluency for Participant 4

\begin{tabular}{|l|l|l|l|}
\hline Quiz & $\begin{array}{l}\text { Quiz } \\
\text { Repetitions }\end{array}$ & $\begin{array}{l}2 \text { min } \\
\text { Fluency }\end{array}$ & $\begin{array}{l}\text { Probe } \\
\text { Score }\end{array}$ \\
\hline Basic Terms 2 & 2 & Yes & 1.00 \\
\hline Restrictive Aids 2 & 1 & Yes & 3.00 \\
\hline Gait Pattern 2 & 1 & No & 2.00 \\
\hline Restrictive Gait Pattern 2 & 2 & No & 3.00 \\
\hline Impairment and Gait Pattern 2 & 3 & No & 4.00 \\
\hline Impairment and Aids 2 & 1 & Yes & 4.00 \\
\hline Problem Solving Strategy & & 3.28 \\
\hline Retention Test & & 2.00 \\
\hline
\end{tabular}

Note. Yes indicates the participant scored at least $9 / 10$ correct in 2 minutes or less. The probe score is the number correct out of 5 possible.

Table 2 Probe Items Answered Correctly for Participant 4

\begin{tabular}{|c|c|c|c|c|c|c|c|c|c|c|c|}
\hline & Probe & Item 1 & Item 1a & Item 2 & Item 2a & Item 3 & Item 3a & Item 4 & Item 4a & Item 5 & Item $5 \mathrm{a}$ \\
\hline \multirow[t]{3}{*}{ Baseline } & Pretest 1 & $\mathrm{O}$ & & & $\mathrm{X}$ & & $\mathrm{X}$ & & $\mathrm{O}$ & $\mathrm{O}$ & \\
\hline & Pretest 2 & & $X$ & & $X$ & & $X$ & $\mathrm{O}$ & & $\mathrm{O}$ & \\
\hline & Pretest 3 & $X$ & & $X$ & & & $X$ & $\mathrm{X}$ & & $X$ & \\
\hline \multirow{3}{*}{$\begin{array}{l}\text { Standard } \\
\text { Quizzes }\end{array}$} & Probe 4 & $\mathrm{X}$ & & $\mathrm{O}$ & & & $\mathrm{X}$ & & $X$ & $\mathrm{O}$ & \\
\hline & \begin{tabular}{|l|} 
Probe 5 \\
\end{tabular} & $\mathrm{X}$ & & $\mathrm{O}$ & & $\mathrm{X}$ & & $\mathrm{O}$ & & & $\mathrm{O}$ \\
\hline & Probe 6 & $X$ & & & $\mathrm{O}$ & & $X$ & & $X$ & & $X$ \\
\hline \multirow{3}{*}{$\begin{array}{l}\text { Fluency } \\
\text { Training }\end{array}$} & Probe 11 & $O$ & & & $\mathrm{O}$ & $\mathrm{X}$ & & 0 & & & $\mathrm{O}$ \\
\hline & Probe 12a & & $\mathrm{O}$ & $\mathrm{O}$ & & $\mathrm{X}$ & & & $\mathrm{O}$ & & $\mathrm{O}$ \\
\hline & Probe $12 b$ & & $\mathrm{O}$ & $\mathrm{O}$ & & $X$ & & & $\mathrm{O}$ & $\mathrm{O}$ & \\
\hline \multirow{3}{*}{$\begin{array}{l}\text { Problem } \\
\text { Solving } \\
\text { Strategy }\end{array}$} & Probe $13 \mathrm{e}$ & & $\mathrm{O}$ & & $\mathrm{O}$ & & $\mathrm{X}$ & & $\mathrm{O}$ & & $\mathrm{X}$ \\
\hline & Probe 13f & $\mathrm{O}$ & & & $\mathrm{O}$ & & $X$ & $\mathrm{O}$ & & $\mathrm{X}$ & \\
\hline & Probe $13 \mathrm{~g}$ & $\mathrm{O}$ & & & $\mathrm{O}$ & & $\mathrm{X}$ & $\mathrm{O}$ & & $\mathrm{X}$ & \\
\hline Follow-U & Probe 14 & $\mathrm{X}$ & & $\mathrm{O}$ & & $\mathrm{X}$ & & $\mathrm{X}$ & & $\mathrm{O}$ & \\
\hline
\end{tabular}

Note. Final 3 probes to show stability at the end of instruction: O correct; X incorrect. Given one item from each pair. 


\section{Appendix I. Results for Participant 5}

Table 1 Quiz Repetitions and Fluency for Participant 5

\begin{tabular}{|l|l|l|l|}
\hline Quiz & $\begin{array}{l}\text { Quiz } \\
\text { Repetitions }\end{array}$ & $\begin{array}{l}\text { 2 min } \\
\text { Fluency }\end{array}$ & $\begin{array}{l}\text { Probe } \\
\text { Score }\end{array}$ \\
\hline Basic Terms 2 & 1 & No & 5.00 \\
\hline Restrictive Aids 2 & 1 & No & 5.00 \\
\hline Gait Pattern 2 & 1 & No & 4.00 \\
\hline Restrictive Gait Pattern 2 & 2 & No & 4.00 \\
\hline Impairment and Gait Pattern 2 & 4 & No & 3.00 \\
\hline Impairment and Aids 2 & 1 & Yes & 4.67 \\
\hline Problem Solving Strategy & & 4.00 \\
\hline Retention Test & & 3.00 \\
\hline
\end{tabular}

Note. Yes indicates the participant scored at least 9/10 correct in 2 minutes or less. The probe score is the number correct out of 5 possible.

Table 2 Probe Items Answered Correctly for Participant 5

\begin{tabular}{|c|c|c|c|c|c|c|c|c|c|c|c|}
\hline & Probe & Item 1 & Item 1a & Item 2 & Item 2a & Item 3 & Item 3a & Item 4 & Item $4 \mathrm{a}$ & Item 5 & Item 5a \\
\hline \multirow[t]{3}{*}{ Baseline } & Pretest 1 & $\mathrm{X}$ & & $\mathrm{O}$ & & $\mathrm{X}$ & & $\mathrm{O}$ & & $\mathrm{O}$ & \\
\hline & Pretest 2 & & $\mathrm{O}$ & $\mathrm{O}$ & & $\mathrm{X}$ & & & $\mathrm{X}$ & $\mathrm{O}$ & \\
\hline & Pretest 3 & $\mathrm{X}$ & & $\mathrm{X}$ & & $\mathrm{X}$ & & $\mathrm{X}$ & & $\mathrm{O}$ & \\
\hline \multirow{3}{*}{$\begin{array}{l}\text { Standard } \\
\text { Quizzes }\end{array}$} & Probe 4 & & $\mathrm{O}$ & $\mathrm{O}$ & & & $\mathrm{O}$ & & $\mathrm{O}$ & & $\mathrm{X}$ \\
\hline & Probe 5 & & $\mathrm{O}$ & & $\mathrm{O}$ & $\mathrm{X}$ & & & $\mathrm{O}$ & & $\mathrm{X}$ \\
\hline & Probe 6 & & $\mathrm{O}$ & & $\mathrm{O}$ & $X$ & & $\mathrm{O}$ & & & $\mathrm{X}$ \\
\hline \multirow{3}{*}{$\begin{array}{l}\text { Fluency } \\
\text { Training }\end{array}$} & Probe 12a & & $\mathrm{O}$ & $\mathrm{O}$ & & $O$ & & & $O$ & 0 & \\
\hline & Probe $12 b$ & $\mathrm{O}$ & & $\mathrm{O}$ & & & $\mathrm{O}$ & $\mathrm{O}$ & & & $\mathrm{O}$ \\
\hline & Probe $12 \mathrm{c}$ & $\mathrm{O}$ & & $\mathrm{O}$ & & & $\mathrm{O}$ & & $\mathrm{O}$ & $\mathrm{X}$ & \\
\hline \multirow{3}{*}{$\begin{array}{l}\text { Problem } \\
\text { Solving } \\
\text { Strategy }\end{array}$} & Probe 13 & & $\mathrm{O}$ & & $\mathrm{O}$ & & $\mathrm{O}$ & $\mathrm{O}$ & & $\mathrm{X}$ & \\
\hline & & & & & & & & & & & \\
\hline & & & & & & & & & & & \\
\hline \multicolumn{2}{|c|}{\begin{tabular}{|l|l|} 
Follow-Up Probe 14
\end{tabular}} & 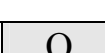 & & 8 & & $X$ & & $\mathrm{X}$ & & 0 & \\
\hline
\end{tabular}

Note. Final 3 probes to show stability at the end of instruction: O correct; X incorrect. Given one item from each pair. 


\section{Appendix J. Results for Participant 6}

Table 1 Quiz Repetitions and Fluency for Participant 6

\begin{tabular}{|l|l|l|l|}
\hline Quiz & $\begin{array}{l}\text { Quiz } \\
\text { Repetitions }\end{array}$ & $\begin{array}{l}2 \text { min } \\
\text { Fluency }\end{array}$ & $\begin{array}{l}\text { Probe } \\
\text { Score }\end{array}$ \\
\hline Basic Terms 2 & 2 & Yes & 3.00 \\
\hline Restrictive Aids 2 & 3 & Yes & 2.00 \\
\hline Gait Pattern 2 & 4 & No & 2.00 \\
\hline Restrictive Gait Pattern 2 & 1 & Yes & 3.00 \\
\hline Impairment and Gait Pattern 2 & 2 & No & 3.00 \\
\hline Impairment and Aids 2 & 1 & No & 3.50 \\
\hline Problem Solving Strategy & \multicolumn{3}{l|}{} \\
\hline Retention Test & & 3.00 \\
\hline
\end{tabular}

Note. Yes indicates the participant scored at least 9/10 correct in 2 minutes or less. The probe score is the number correct out of 5 possible.

Table 2 Probe Items Answered Correctly for Participant 6

\begin{tabular}{|c|c|c|c|c|c|c|c|c|c|c|c|}
\hline & Probe & Item 1 & Item 1a & Item 2 & Item $2 \mathrm{a}$ & Item 3 & Item 3a & Item 4 & Item $4 \mathrm{a}$ & Item 5 & Item 5a \\
\hline \multirow[t]{3}{*}{ Baseline } & Pretest 1 & & $\mathrm{X}$ & $\mathrm{O}$ & & & $\mathrm{X}$ & $\mathrm{O}$ & & & $\mathrm{O}$ \\
\hline & Pretest 2 & & $\mathrm{O}$ & & $\mathrm{O}$ & $\mathrm{X}$ & & & $\mathrm{O}$ & $\mathrm{O}$ & \\
\hline & Pretest 3 & & $X$ & $\mathrm{O}$ & & $X$ & & & $\mathrm{O}$ & $\mathrm{O}$ & \\
\hline \multirow{4}{*}{$\begin{array}{l}\text { Fluency } \\
\text { Training }\end{array}$} & & & & & & & & & & & \\
\hline & Probe 11 & & $X$ & $\mathrm{O}$ & & & $\mathrm{O}$ & & $X$ & $\mathrm{O}$ & \\
\hline & Probe 12A & & $\mathrm{X}$ & & $\mathrm{O}$ & & $\mathrm{O}$ & $\mathrm{O}$ & & & $\mathrm{O}$ \\
\hline & Probe 12B & $\mathrm{X}$ & & $\mathrm{O}$ & & & $\mathrm{O}$ & $\mathrm{X}$ & & $\mathrm{O}$ & \\
\hline & & & & & & & & & & & \\
\hline \multirow{3}{*}{$\begin{array}{l}\text { Problem } \\
\text { Solving } \\
\text { Strategy } \\
\end{array}$} & Probe 13a & $\mathrm{X}$ & & & $\mathrm{O}$ & & $\mathrm{O}$ & $X$ & & & $\mathrm{O}$ \\
\hline & Probe 13b & $\mathrm{X}$ & & & $\mathrm{O}$ & & $\mathrm{O}$ & & $\mathrm{X}$ & & $\mathrm{O}$ \\
\hline & & & & & & & & & & & \\
\hline Follow-Up & Probe 14 & $X$ & & $X$ & & $\mathrm{X}$ & & $\mathrm{X}$ & & $\mathrm{X}$ & \\
\hline
\end{tabular}

Note. Final 3 probes to show stability at the end of instruction: O correct; X incorrect. Given one item from each pair. 


\section{Appendix K. Results for Participant 7}

Table 1 Quiz Repetitions and Fluency for Participant 7

\begin{tabular}{|c|c|c|c|}
\hline Quiz & $\begin{array}{l}\text { Quiz } \\
\text { Repetitions }\end{array}$ & $\begin{array}{l}2 \text { min } \\
\text { Fluency }\end{array}$ & $\begin{array}{l}\text { Probe } \\
\text { Score }\end{array}$ \\
\hline Basic Terms 2 & 2 & Yes & 0.00 \\
\hline Restrictive Aids 2 & 1 & Yes & 2.00 \\
\hline Gait Pattern 2 & 4 & No & 1.00 \\
\hline Restrictive Gait Pattern 2 & 1 & Yes & 2.00 \\
\hline Impairment and Gait Pattern 2 & 2 & No & 4.00 \\
\hline Impairment and Aids 2 & 1 & Yes & 3.00 \\
\hline \multicolumn{3}{|l|}{ Problem Solving Strategy } & 3.75 \\
\hline \multicolumn{3}{|l|}{ Retention Test } & 2.00 \\
\hline
\end{tabular}

Note. Yes indicates the participant scored at least 9/10 correct in 2 minutes or less. The probe score is the number correct out of 5 possible.

Table 2 Probe Items Answered Correctly for Participant 7

\begin{tabular}{|c|c|c|c|c|c|c|c|c|c|c|c|}
\hline & Probe & Item 1 & Item 1a & Item 2 & Item $2 \mathrm{a}$ & Item 3 & Item $3 \mathrm{a}$ & Item 4 & Item $4 \mathrm{a}$ & Item 5 & Item 5a \\
\hline \multirow[t]{4}{*}{ Baseline } & Pretest 1 & & $X$ & & $X$ & $\mathrm{X}$ & & $\mathrm{O}$ & & $\mathrm{O}$ & \\
\hline & Pretest 2 & $\mathrm{O}$ & & $\mathrm{X}$ & & & $\mathrm{X}$ & & $\mathrm{O}$ & $X$ & \\
\hline & Pretest 3 & & $\mathrm{X}$ & & $\mathrm{O}$ & $\mathrm{O}$ & & & $\mathrm{O}$ & $\mathrm{X}$ & \\
\hline & Pretest 4 & $\mathrm{O}$ & & & $\mathrm{X}$ & $\mathrm{X}$ & & $\mathrm{O}$ & & $X$ & \\
\hline \multirow{4}{*}{$\begin{array}{l}\text { Fluency } \\
\text { Training }\end{array}$} & & & & & & & & & & & \\
\hline & Probe 10 & & $X$ & $\mathrm{O}$ & & & $X$ & & $\mathrm{X}$ & $\mathrm{O}$ & \\
\hline & Probe 11 & & $\mathrm{O}$ & & $\mathrm{O}$ & $\mathrm{X}$ & & $\mathrm{O}$ & & $\mathrm{O}$ & \\
\hline & Probe 12 & $X$ & & & $\mathrm{O}$ & & $\mathrm{X}$ & $\mathrm{O}$ & & $\mathrm{O}$ & \\
\hline & & & & & & & & & & & \\
\hline \multirow{3}{*}{$\begin{array}{l}\text { Problem } \\
\text { Solving } \\
\text { Strategy }\end{array}$} & Probe $13 b$ & & $\mathrm{O}$ & & $\mathrm{O}$ & & $\mathrm{X}$ & $\mathrm{O}$ & & $\mathrm{O}$ & \\
\hline & Probe $13 \mathrm{c}$ & & $\mathrm{O}$ & & $\mathrm{O}$ & $\mathrm{X}$ & & & $\mathrm{O}$ & $\mathrm{O}$ & \\
\hline & Probe $13 \mathrm{~d}$ & $\mathrm{O}$ & & & $\mathrm{O}$ & $X$ & & & $\mathrm{O}$ & & $\mathrm{O}$ \\
\hline Follow-U & Probe 14 & $X$ & & $\mathrm{O}$ & & $\mathrm{X}$ & & $\mathrm{O}$ & & $X$ & \\
\hline
\end{tabular}

Note. Final 3 probes to show stability at the end of instruction: O correct; X incorrect. Given one item from each pair. 


\section{Appendix L. Results for Participant 8}

Table 1 Quiz Repetitions and Fluency for Participant 8

\begin{tabular}{|l|l|l|l|}
\hline Quiz & $\begin{array}{l}\text { Quiz } \\
\text { Repetitions }\end{array}$ & $\begin{array}{l}\text { 2 min } \\
\text { Fluency }\end{array}$ & $\begin{array}{l}\text { Probe } \\
\text { Score }\end{array}$ \\
\hline Basic Terms 2 & 3 & Yes & 2.00 \\
\hline Restrictive Aids 2 & 1 & Yes & 2.00 \\
\hline Gait Pattern 2 & 1 & No & 3.00 \\
\hline Restrictive Gait Pattern 2 & 1 & Yes & 2.00 \\
\hline Impairment and Gait Pattern 2 & 3 & No & 3.00 \\
\hline Impairment and Aids 2 & 3 & Yes & 5.00 \\
\hline Retention Test & & 2.00 \\
\hline
\end{tabular}

Note. Yes indicates the participant scored at least 9/10 correct in 2 minutes or less. The probe score is the number correct out of 5 possible.

Table Probe Responses for Participant 8

\begin{tabular}{|c|c|c|c|c|c|c|c|c|c|c|c|}
\hline & Probe & Item 1 & Item 1a & Item 2 & Item $2 \mathrm{a}$ & Item 3 & Item 3a & Item 4 & Item 4a & Item 5 & Item 5a \\
\hline \multirow[t]{3}{*}{ Baseline } & Pretest 1 & $X$ & & & $X$ & & $X$ & $X$ & & $\mathrm{O}$ & \\
\hline & Pretest 2 & $X$ & & & $\mathrm{O}$ & $X$ & & $\mathrm{O}$ & & & $\mathrm{X}$ \\
\hline & Pretest 3 & & $\mathrm{O}$ & & $\mathrm{O}$ & & & $\mathrm{O}$ & & & $X$ \\
\hline \multirow{3}{*}{$\begin{array}{l}\text { Standard } \\
\text { Quizzes }\end{array}$} & Probe $6 \mathrm{a}$ & & $\mathrm{X}$ & $\mathrm{O}$ & & $\mathrm{O}$ & & $\mathrm{O}$ & & & $\mathrm{O}$ \\
\hline & Probe $6 \mathrm{~b}$ & & $\mathrm{X}$ & & $\mathrm{O}$ & & $\mathrm{X}$ & $\mathrm{O}$ & & $\mathrm{X}$ & \\
\hline & Probe 6c & $\mathrm{X}$ & & & $X$ & $\mathrm{X}$ & & & $\mathrm{O}$ & & $\mathrm{X}$ \\
\hline \multirow{3}{*}{$\begin{array}{l}\text { Fluency } \\
\text { Training }\end{array}$} & Probe 12a & $\mathrm{O}$ & & $\mathrm{O}$ & & $\mathrm{O}$ & & $\mathrm{O}$ & & & $\mathrm{O}$ \\
\hline & Probe $12 \mathrm{~b}$ & & $\mathrm{O}$ & & $\mathrm{O}$ & & $\mathrm{O}$ & $\mathrm{O}$ & & $\mathrm{O}$ & \\
\hline & Probe $12 \mathrm{c}$ & $\mathrm{O}$ & & $\mathrm{O}$ & & & $\mathrm{O}$ & & $\mathrm{O}$ & & $\mathrm{O}$ \\
\hline \multicolumn{2}{|c|}{\begin{tabular}{|l|l|} 
Follow-Up & Probe 14 \\
\end{tabular}} & $\mathrm{X}$ & & $\mathrm{O}$ & & $\mathrm{X}$ & & $\mathrm{X}$ & & $\mathrm{O}$ & \\
\hline
\end{tabular}

Note. Final 3 probes to show stability at the end of instruction: O correct; X incorrect. Given one item from each pair. 


\section{Appendix M. Results for Participant 9}

Table 1 Quiz Repetitions and Fluency for Participant 9

\begin{tabular}{|l|l|l|l|}
\hline Quiz & $\begin{array}{l}\text { Quiz } \\
\text { Repetitions }\end{array}$ & $\begin{array}{l}2 \text { min } \\
\text { Fluency }\end{array}$ & $\begin{array}{l}\text { Probe } \\
\text { Score }\end{array}$ \\
\hline Basic Terms 2 & 1 & Yes & 1.00 \\
\hline Restrictive Aids 2 & 2 & Yes & 4.00 \\
\hline Gait Pattern 2 & 2 & No & 2.00 \\
\hline Restrictive Gait Pattern 2 & 1 & Yes & 2.00 \\
\hline Impairment and Gait Pattern 2 & 3 & No & 3.00 \\
\hline Impairment and Aids 2 & 1 & Yes & 1.00 \\
\hline Retention Test & \multicolumn{3}{|l}{} \\
\hline
\end{tabular}

Note. Yes indicates the participant scored at least $9 / 10$ correct in 2 minutes or less. The probe score is the number correct out of 5 possible.

Table Probe Responses for Participant 9

\begin{tabular}{|c|c|c|c|c|c|c|c|c|c|c|c|}
\hline & Probe & Item 1 & Item 1a & Item 2 & Item $2 \mathrm{a}$ & Item 3 & Item $3 \mathrm{a}$ & Item 4 & Item $4 \mathrm{a}$ & Item 5 & Item 5a \\
\hline \multirow[t]{4}{*}{ Baseline } & Pretest 1 & & $\mathrm{O}$ & $X$ & & $\mathrm{X}$ & & $X$ & & & $\mathrm{O}$ \\
\hline & \begin{tabular}{|l|} 
Pretest 2 \\
\end{tabular} & $\mathrm{X}$ & & $\mathrm{X}$ & & & $\mathrm{X}$ & $\mathrm{X}$ & & $\mathrm{X}$ & \\
\hline & Pretest 3 & $\mathrm{X}$ & & $\mathrm{X}$ & & & & $\mathrm{O}$ & $\mathrm{O}$ & & $\mathrm{X}$ \\
\hline & Pretest 4 & & $\mathrm{X}$ & & $\mathrm{X}$ & $\mathrm{O}$ & & $\mathrm{O}$ & & $\mathrm{X}$ & \\
\hline & & & & & & & & & & & \\
\hline \multirow{3}{*}{$\begin{array}{l}\text { Fluency } \\
\text { Training }\end{array}$} & Probe 10 & $\mathrm{X}$ & & & $\mathrm{O}$ & & $\mathrm{X}$ & $\mathrm{X}$ & & & $\mathrm{O}$ \\
\hline & Probe 11 & $\mathrm{O}$ & & & $\mathrm{O}$ & $X$ & & $\mathrm{X}$ & & & $\mathrm{O}$ \\
\hline & Probe 12 & $\mathrm{X}$ & & $\mathrm{O}$ & & $\mathrm{X}$ & & & $\mathrm{X}$ & $X$ & \\
\hline & & & & & & & & & & & \\
\hline \multirow{3}{*}{$\begin{array}{l}\text { Problem } \\
\text { Solving } \\
\text { Strategy }\end{array}$} & Probe13c & ---- & & & $\mathrm{O}$ & & $\mathrm{O}$ & $\mathrm{O}$ & & & $\mathrm{X}$ \\
\hline & Probe $13 \mathrm{~d}$ & & $\mathrm{O}$ & & $\mathrm{O}$ & & $\mathrm{O}$ & & $\mathrm{X}$ & & $\mathrm{X}$ \\
\hline & Probe $13 \mathrm{e}$ & & $\mathrm{O}$ & & $\mathrm{X}$ & $\mathrm{O}$ & & $\mathrm{O}$ & & $X$ & \\
\hline Follow-U & Probe 14 & $\mathrm{X}$ & & $\mathrm{O}$ & & $\mathrm{O}$ & & $\mathrm{X}$ & & $X$ & \\
\hline
\end{tabular}

Note. Final 3 probes to show stability at the end of instruction: O correct; $\mathrm{X}$ incorrect. Given one item from each pair. 


\section{Curriculum Vita}

\section{Beverly R. Born}

RR 3, Box 277C, Fairmont, WV 26554

304-367-0440 (H), 304-367-4042 (O)

\section{Present Position}

Coordinator and Assistant Professor

Physical Therapist Assistant Program, Fairmont State Community and Technical College

\section{Education}

West Virginia University, Morgantown WV

A.B. Psychology, 1976

B.S. Physical Therapy, 1977

M.A. Public Administration, 1991

Ed.D. Educational Psychology, degree anticipated August 2003

Intern to Assistant Vice President of Curriculum and Instruction (1990-91)

West Virginia University, Morgantown WV

\section{Continuing Education}

Courses attended within past five years:

Teaching Skills

Teaching skills workshop, 12 hours

Classroom Management Workshop (2 hours)

IPSI Workshop(2 days)

Teaching with Style Video Conference

National Assessment Conference (3 days)

WVNET Faculty Boot Camp (Web teaching), 40 contact hours

WebCT 3.5 Advanced Topics, 16 contact hours

\section{Physical Therapy Content}

Balance Workshop (1 day)

Risk Management in Physical Therapy, 3 contact hours

Physical Therapy in the Schools, 5.5 contact hours

Workshop for Clinical Instructors, 3 contact hours

Forum on Professional Behaviors in Physical Therapy, $\quad 2.5$ days 
Administration in Transition to the 21st Century Colloquium, State of Health Care Vestibular Rehabilitation, 10 Contact hours

The Aging of the Brain, 6 contact hours

Understanding Anger, Diagnosis \&Treatment, 6 contact hours

The Older Adult: What Works? 10 contact hours

Current Management of Osteoporosis, 4.5 contact hours

Updates in Prosthetics and Orthotics, 3 contact hours

\section{Professional Licensure}

West Virginia Physical Therapy License \#265

\section{Employment and Positions Held}

1995 to Present Assistant Professor and Coordinator of PTA Program

Fairmont State Community and Technical College Fairmont, WV

1990-1995 Independent Contract Physical Therapist in public school, home health, and long term care settings.

1978-1987 Clinical Associate Professor, Unsalaried

West Virginia University

1977- 1987 Chief Physical Therapist

Fairmont General Hospital, Inc. Fairmont, WV

\section{Membership in Scientific/Professional/Honorary Societies}

American Physical Therapy Association.

West Virginia Physical Therapy Association

Phi Beta Kappa (1975)

\section{Service to the College}

1997-1998 Student Hearing Committee

Search Committee for Health Careers School Chair

Shared Governance Committee, School of Health Careers

FSC PTA Program Advisory Committee

1998-1999 Student Hearing Committee 
Faculty Grievance Committee

College Assessment Committee

FSC PTA Program Advisory Committee

1999-2000 Faculty Grievance Committee

College Assessment Committee

FSC PTA Program Advisory Committee

2000-2001 College Assessment Committee

Search Committee for Caperton Center Director

FSC PTA Program Advisory Committee

2001-2002 College Assessment Committee

FSC \& TC Faculty Assembly

Faculty Assembly Curriculum Committee

FSC PTA Program Advisory Committee

2002-2003 College Assessment Committee

FSC \& TC Faculty Assembly

Faculty Assembly Curriculum Committee

FSC PTA Program Advisory Committee

\section{Current Teaching Responsibility in PTA Program}

PTA 100, Introduction to Physical Therapy

PTA 101, Patient and Professional Relationship

PTA 102, Introduction to Patient Care

PTA 103, Physical Agents I (co-taught)

PTA 104, Physical Agents II (co-taught)

PTA 105, Kinesiology

PTA 200, Therapeutic Exercise (co-taught)

PTA 201, Orthopedics 